\title{
Sall2 is required for proapoptotic Noxa expression and genotoxic stress-induced apoptosis by doxorubicin
}

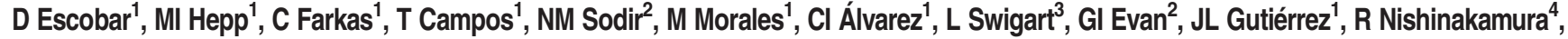 \\ AF Castro ${ }^{1}$ and R Pincheira ${ }^{*, 1}$
}

The Sall2 transcription factor is deregulated in several cancers; however, little is known about its cellular functions, including its target genes. Recently, we demonstrated that p53 directly regulates Sall2 expression under genotoxic stress. Here, we investigated the role of Sall2 in the context of cellular response to genotoxic stress. In addition, we further examined the Sall2-p53 relationship during genotoxic stress in primary mouse embryo fibroblasts (MEFs), which are derived from Sall2 knockout mice separately, or in combination with the p53ERTAM knock-in mice. We found that the levels of Sall2 mRNA and protein are dynamically modulated in response to doxorubicin. At early times of stress, Sall2 is downregulated, but increases under extension of the stress in a p53independent manner. Based on caspase-3/7 activities, expression of cleaved poly (ADP-ribose) polymerase, expression of cleaved caspase-3 and induction of proapoptotic proteins, Sall2 expression was correlated with cellular apoptosis. Consequently, Sall2 ${ }^{-1-}$ MEFs have decreased apoptosis, which relates with increased cell viability in response to doxorubicin. Importantly, Sall2 was required for apoptosis even in the presence of fully activated p53. Searching for putative Sall2 targets that could mediate its role in apoptosis, we identified proapoptotic NOXA/PMAIP1 (phorbol-12-myristate-13-acetate-induced protein 1). We demonstrated that Sall2 positively regulates Noxa promoter activity. Conserved putative Sall2-binding sites at the NOXA promoter were validated in vitro by electrophoretic mobility shift assay and in vivo by ChIP experiments, identifying NOXA as a novel Sall2 target. In agreement, induction of Noxa protein and mRNA in response to doxorubicin was significantly decreased in Sall2 ${ }^{--}$MEFs. In addition, studies in leukemia Jurkat T cells support the existence of the Sall2/Noxa axis, and the significance of this axis on the apoptotic response to doxorubicin in cancer cells. Our study highlights the relevance of Sall2 in the apoptotic response to extended genotoxic stress, which is important for understanding its role in normal physiology and disease.

Cell Death and Disease (2015) 6, e1816; doi:10.1038/cddis.2015.165; published online 16 July 2015

Deregulation of the Sall2 transcription factor is associated with the development of human diseases, including cancer, ocular coloboma and Alport syndrome..$^{1-4}$ However, Sall2 normal function, regulation and immediate target genes are not well known, making it difficult to understand its role in various diseases.

SALL2 is a member of the Spalt/Sal family of transcription factors characterized by their role in organ development and conserved from Caenorhabditis elegans to humans. ${ }^{5-7}$ Sall2deficient mice were previously reported to have no apparent abnormal phenotype when bred on a C57BL/6 genetic background; however, a strain-specific incidence of neural tube defects and perinatal lethality were reported when bred on mixed genetic backgrounds. ${ }^{8,9}$ Recently, it was demonstrated that Sall2 has a role in eye morphogenesis and a SALL2 gene mutation was associated with coloboma, a congenital eye defect. ${ }^{2,10}$ A deleterious SALL2 mutation was also associated with Alport syndrome, a renal disease, ${ }^{1}$ suggesting that Sall2 could have a role in kidney development.

Evidences for Sall2 association with cancer are increasing, but are still controversial. Several studies suggest a tumor

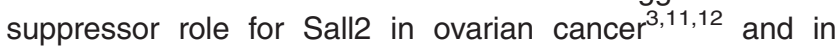
primary acute myeloid leukemia. ${ }^{13}$ However, Sall2 is found upregulated in Wilm's tumor, ${ }^{14}$ synovial sarcoma, ${ }^{15,16}$ oral cancer $^{17,18}$ and testicular cancer, ${ }^{19}$ and is one of the four neurodevelopmental transcription factors essential for glioblastoma propagation. ${ }^{4}$ The molecular mechanisms underlying the role of Sall2 as a tumor suppressor in certain types of cancer and its deregulation in others are still unknown.

To understand the role of Sall2 in normal and disease states, it is essential to define Sall2 targets under different cell contexts. Sall2 targets identified to date include the cell cycle regulatory gene $p 21^{\text {WAF }}$ (protein 21 wild-type p53 activation

\footnotetext{
1Departamento de Bioquímica y Biología Molecular, Facultad de Ciencias Biológicas, Universidad de Concepción, Concepción, Chile; ${ }^{2}$ Department of Biochemistry, University of Cambridge, Cambridge, UK; ${ }^{3}$ Helen Diller Family Comprehensive Cancer Center, University of California San Francisco, San Francisco, CA 94115, USA and ${ }^{4}$ Department of Kidney Development, Institute of Molecular Embryology and Genetics, Kumamoto University, Kumamoto, Japan

*Corresponding author: R Pincheira, Departamento de Bioquimica y Biología Molecular, Facultad de Ciencias Biológicas, Universidad de Concepción, Victor Lamas 1290 , Concepción 4070386, Bio Bio, Chile. Tel: +56 41 2203815; Fax: +56 41 2239687; E-mail: ropincheira@udec.cl

Abbreviations: 4-OHT, 4-hydroxytamoxifen; BAX, BCL2-associated X protein; BAD, BCL2-associated death promoter; BCL2, B-cell lymphoma 2; BH3, BCL2 homology domain 3; ChIP, chromatin immunoprecipitation; DMEM, Dulbecco's Modified Eagle's Medium; DMSO, dimethyl sulfoxide; EMSA, electrophoretic mobility shift assay; ER/ER, estrogen receptor; EtOH, ethanol; FBS, fetal bovine serum; GFP, green fluorescent protein; HOSE, human ovarian surface epithelial; MEF, mouse embryo fibroblast; MG132, carbobenzoxy-Leu-Leu-leucinal; p21 ${ }^{\text {WAF }}$, protein 21 wild-type p53 activation factor; PARP, poly (ADP-ribose) polymerase; PMAIP1, phorbol-12myristate-13-acetate-induced protein 1

Received 27.1.15; revised 13.5.15; accepted 15.5.15; Edited by A Stephanou
} 
factor), the proapoptotic gene $B A X$ (B-cell lymphoma 2 (BCL2)-associated $X$ protein) and the proto-oncogene $c-M y c$. Although Sall2 upregulates $\mathrm{p} 21^{\mathrm{WAF}}$ and BAX, it represses c-Myc. ${ }^{12,20,21}$ Sall2 targets were identified in a p53-independent context, with Sall2 and p53 having common targets. The p53 gene is mutated in over $50 \%$ of human cancers (http://www-p53.iarc.fr/). In response to various types of stress, signaling pathways converge to induce transcriptional regulation by p53 of target genes involved in cellular responses including cell cycle arrest, apoptosis, senescence, autophagy, DNA repair and central metabolism. ${ }^{22,23}$ p53 prevents tumor formation through transcriptional-dependent and -independent mechanisms. ${ }^{24-26}$ We recently demonstrated that SALL2 is also a p53 target gene. At early times of genotoxic stress, p53 downregulates Sall2 by directly binding to the SALL2 promoter. ${ }^{27}$ Here, we investigated the role of Sall2 in the cellular response to doxorubicin and further examined the Sall2-p53 relationship during genotoxic stress in mouse embryonic fibroblasts (MEFs) derived from Sall2 knockout mice separately or in combination with the p53ERTAM knock-in mice. We show that Sall2 is required for full apoptotic response to doxorubicin, and demonstrate that apoptosis is significantly decreased in Sall2-deficient cells even in the presence of activated p53. More importantly, we identified Noxa, a member of the Bcl-2 homology domain 3 (BH3)-only proteins, ${ }^{28}$ as a novel Sall2 target. We demonstrate that Sall2 binds to and transactivates the NOXA promoter under genotoxic stress in vitro and in vivo. Finally, we show that the Sall2/Noxa axis is also important for the cell death response to doxorubicin in Jurkat T cells, supporting the significance of this axis in a cancer cell context. This new data supports the tumor suppressor function of Sall2, and enhances the understanding of Sall2 role in the context of genotoxic stress.

\section{Results}

Sall2 expression is dynamically regulated during doxorubicin treatment. We recently demonstrated that Sall2 is downregulated by p53 during genotoxic stress. ${ }^{27}$ To understand the role of Sall2 during this stress, we used primary Sall2 wild-type $\left(\right.$ Sall $\left.^{+/+}\right)$and Sall2 knockout ${ }^{9}$ $\left(\right.$ Sall2 $\left.{ }^{-/}\right)$MEFs, and primary MEFs derived from Sall2 ${ }^{+/-}$ model crossed with a conditional p53ERTAM knock-in $\left(p 53^{E R / E R}\right)$ model described previously. ${ }^{29} p 53^{E R / E R}$ mice and cells derived from it can be reversibly and rapidly switched between p53 wild-type and knockout states by, respectively, administration or withdrawal of 4-hydroxytamoxifen $(4-\mathrm{OHT}) .^{29-32}$ We used these cells to investigate p53dependent and -independent Sall2 responses.

We treated Sall2 ${ }^{+/+}$MEFs and $p 53^{E R / E R}$; Sall $2^{+/+}$MEFs (in the presence of 4-OHT for p53 wild-type state) with $1 \mu \mathrm{M}$ doxorubicin and isolated RNA after different times of treatment. Consistent with our previous report, we observed a dynamic regulation of Sall2 expression over the treatment period. Sall 2 mRNA levels significantly decreased after $2 \mathrm{~h}$, but they recovered and increased after $12 \mathrm{~h}$ in both cell models (Figures 1a and b). The changes on Sall2 expression were also observed using a lower dose of doxorubicin $(0.5 \mu \mathrm{M})$ (Supplementary Figure 1).

To determine if the increase of Sall2 mRNA levels correlates with the expression of potentially functional Sall2, we performed subcellular fractionation of MEFs exposed to $1 \mu \mathrm{M}$ doxorubicin and evaluated Sall2 protein expression and location. According to the mRNA results, Sall2 protein increased at $16 \mathrm{~h}$ and localized exclusively at the cell nucleus (Figure 1c). As expected, doxorubicin induced p53 activation, ${ }^{33-35}$ evidenced by an increase on p53 levels and its phosphorylation at Ser18 (p-p53) in the nucleus. Doxorubicin mainly induces cell cycle arrest in MEFs; ${ }^{33,34,36,37}$ still, several reports indicate that extended doxorubicin treatment (using $1 \mu \mathrm{M}$ or higher concentration) could result in apoptosis. $^{38-40}$ We detected nuclear cleaved caspase-3 between 16 and $24 \mathrm{~h}$ of doxorubicin treatment. As caspase3 is cleaved during apoptosis and is translocated into the nucleus to cleave its substrates, ${ }^{41,42}$ our results suggest that the Sall2 upregulation correlates with apoptosis.

Sall2 expression is required for doxorubicin-induced apoptosis of MEFs. To determine whether Sall2 contributes to apoptosis under genotoxic stress, we exposed Sall2 ${ }^{+/+}$and Sall2 ${ }^{-/}$MEFs to doxorubicin $(1 \mu \mathrm{M})$ for $16 \mathrm{~h}$, and then examined apoptosis through caspase-3/7 activity. Figure $2 \mathrm{a}$ shows that Sall2 $2^{--}$cells are more resistant to apoptosis compared with Sall2 ${ }^{+/+}$MEFs. Sall2 ${ }^{+/+}$MEFs showed a statistically significant increase in caspase-3/7 activity ( $>3$ fold) compared with untreated control cells, whereas two independent Sall2 ${ }^{-/}$MEFs had a slight increase in apoptosis. This indicates that Sall2-competent cells are more prone to apoptosis induced by genotoxic stress compared with Sall2-deficient cells.

Because of the important role of p53 in genotoxic stressinduced apoptosis, we analyzed whether the role of Sall2 is dependent on p53 using Sall $2^{+/}$or Sall ${ }^{-/}$MEFs in combination with $p 53^{E R / E R}$ MEFs. In the cell model, p53 is expressed in the presence of ethanol $(\mathrm{EtOH})$ but remains inactive even when an activating signal such as doxorubicin is added; in the presence of 4-OHT, p53 is expressed and has the capacity to be activated by doxorubicin but not by the addition of dimethyl sulfoxide (DMSO). ${ }^{29}$ We exposed conditional $p 53^{E R / E R} ; S_{\text {Sall }}^{+/+}$and $p 53^{E R / E R} ;$ Sall2 ${ }^{-/-}$MEFs to doxorubicin, and measured apoptosis as above. The $p 53^{E R / E R}$; Sall2 ${ }^{--}$MEFs also showed significantly lower levels of apoptosis compared with the p53 $3^{E R / E R}$; Sall $2^{+/+}$MEFs either in the absence (EtOH) or presence (4-OHT) of fully active p53 (Figure 2b, compare bars 3-4 and 7-8). The residual apoptotic activity in the absence of 4-OHT may indicate that Sall2 affects apoptosis independently of p53. However, the apoptotic response is significantly increased when p53 and Sall2 are present (Figure 2b; > 4.5-fold, bar 7). Additionally, we analyzed the expression of apoptotic markers over the time of treatment with doxorubicin in $p 53^{E R / E R}$; Sall $2^{+/+}$and $p 53^{E R / E R}$; Sall2 $2^{-/}$ MEFs treated with 4-OHT. The results shown in Figure $2 \mathrm{c}$ indicate that in response to doxorubicin, p53 increases in both Sall2 $2^{+/+}$and Sall2 ${ }^{/-}$MEFs. However, apoptosis is decreased in the Sall ${ }^{-/}$MEFs, evidenced by the low levels of cleaved caspase-3 and poly (ADP-ribose) polymerase (PARP), especially after $12 \mathrm{~h}$ of treatment. Consistent with a role for Sall2 in 
a

MEF Sall2 +/+

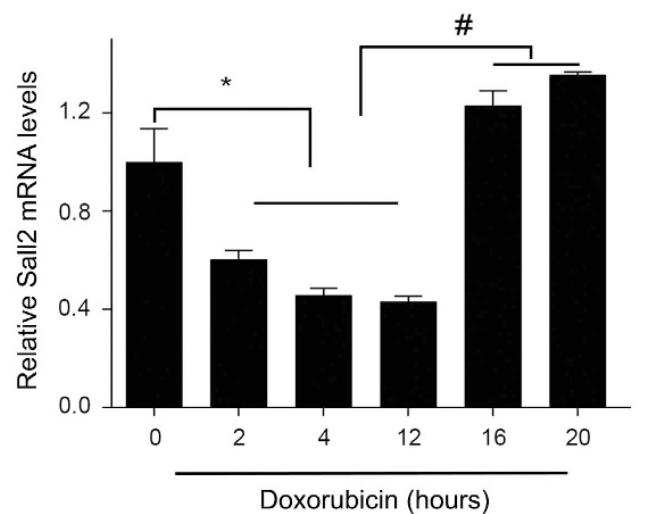

C

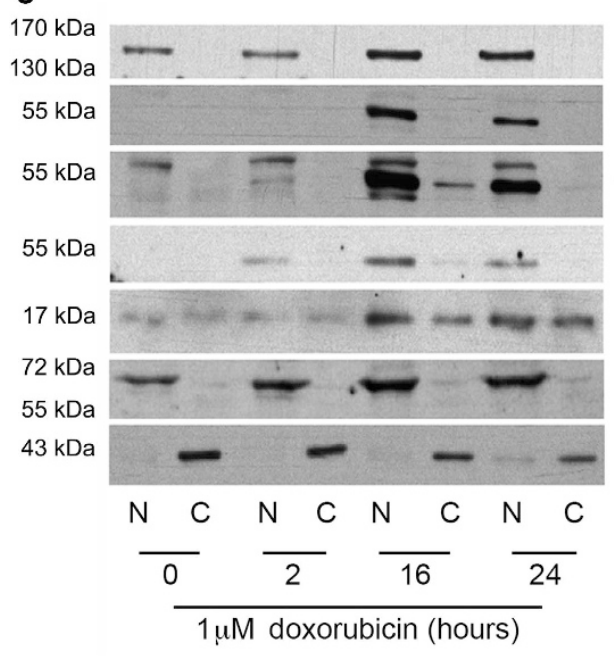

b

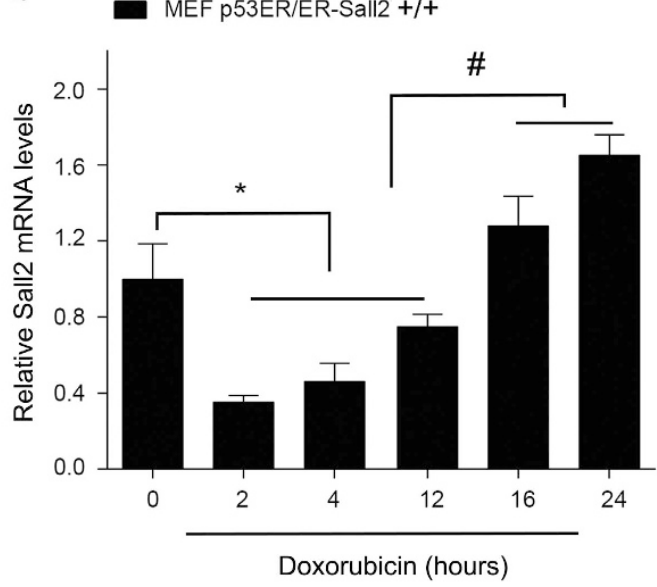

Sall2

p53 (short exposure)

p53 (long exposure)

p-p53 (Ser15)

cleaved caspase 3

Iamin B1

MEK1

Figure 1 Dynamic regulation of Sall2 under genotoxic stress induced by doxorubicin. Wild-type Sall/2++ (a) or $p 53^{\text {ER/ER} ; ~ S a l l ~} 2^{+/+}$(b) MEFs were exposed to $1 \mu \mathrm{M}$ doxorubicin for various times. In (b), before doxorubicin treatment, $p 53^{E R / E R}$; Sall2 ${ }^{+/+}$MEFs were treated for $4 \mathrm{~h}$ with $4-\mathrm{OHT} 100 \mathrm{nM}$ to allow p53 functionality. Sall2 mRNA levels were measured by quantitative real-time PCR (qPCR) relative to cyclophilin $A$. Values from triplicate samples are representative of three independent experiments. Expression at time 0 was defined as 1. Each bar represents the mean \pm S.D. ${ }^{*} P<0.05$ for decrease of Sall2 relative to $t=0 \mathrm{~h} ;{ }^{\#} P<0.05$ for increase of Sall2 relative to $t=12 \mathrm{~h}$. (c) Sall $2^{+/+}$MEFs were exposed to $1 \mu \mathrm{M}$ doxorubicin for the indicated times. Lysates were collected and subcellular fractionation was performed to obtain nuclear (N) and cytoplasmic (C) fractions. Levels of Sall2, total and activated (Ser18) p53 and cleaved caspase-3 were determined by western blot using specific antibodies. Lamin B1 and MEK1 are nuclear and cytoplasmic markers, respectively. The figure is representative of two independent experiments

cell death response, cell viability was increased in Sall ${ }^{-1-}$ MEFs between 16-48 $\mathrm{h}$ of doxorubicin treatment (Figure 2d), which correlated with the decreased apoptotic response observed in Figures $2 \mathrm{a}-\mathrm{c}$. Taken together, our data indicate that Sall2 is required for the doxorubicin-induced p53-dependent apoptosis of MEFs, but Sall2 may induce apoptosis independently of p53. Consistent with the later, we found no difference in the increase of Sall2 expression in response to doxorubicin between p53-deficient (EtOH) and p53-active (4-OHT) MEFs (Figure 2e). The known p53 targets p21 WAF and BAX substantially increased after doxorubicin treatment in MEFs incubated with 4-OHT; however, consistent with being reported as Sall2 targets, ${ }^{12,20}$ the increase of $\mathrm{p} 21^{\mathrm{WAF}}$ and BAX were almost lost in Sall ${ }^{-1}$ MEFs, even under the activation of $\mathrm{p} 53$ by 4-OHT and doxorubicin (Figure 2d). These experiments indicate that Sall2 is required for $\mathrm{p} 21^{\mathrm{WAF}}$ - and BAX-induced expression.
Sall2 is required for Noxa expression under genotoxic stress, and activates NOXA promoter. We further investigated the apoptotic response to doxorubicin by analyzing the expression of other proapoptotic proteins. In addition to BAX, we analyzed the expression of BAD (BCL2-associated death promoter) and Noxa. In parallel, we analyzed the levels of total and phosphorylated p53 (Ser18). As indicated previously, Figure $3 a$ shows that $p 53$ levels and activity increase in response to doxorubicin in both Sall2 $2^{+/+}$and Sall ${ }^{-/-}$ MEFs. BAD protein levels also increased in response to doxorubicin; however, the induction of BAX and Noxa were decreased in the absence of Sall2. Consistent with previous experiments, the levels of cleaved caspase-3 also decreased in Sall ${ }^{-1-}$ MEFs. BAX has been previously reported as a Sall2 target gene, ${ }^{20}$ but the observed correlation between Noxa and Sall2 expression is novel. 


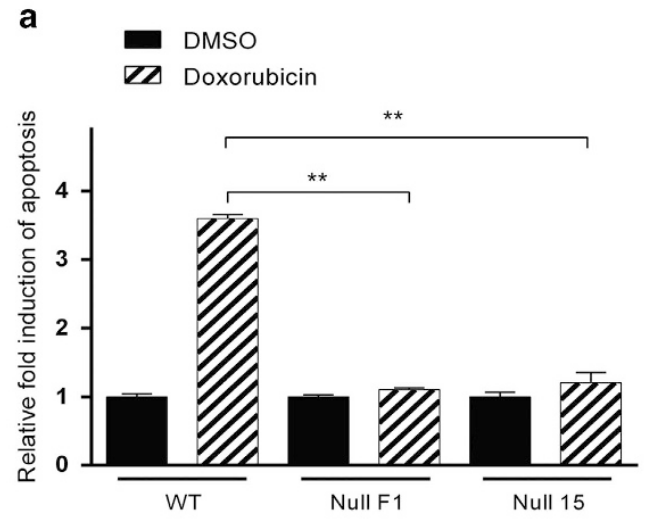

C

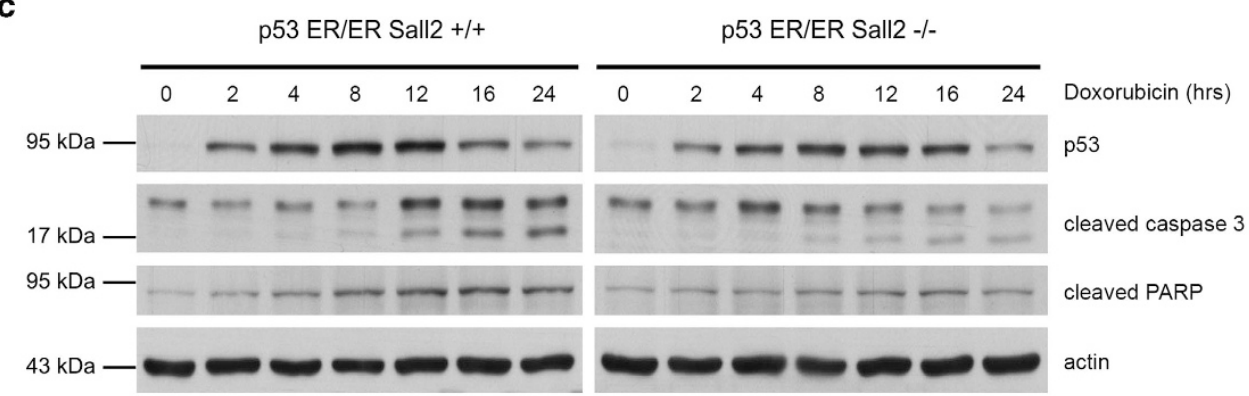

d

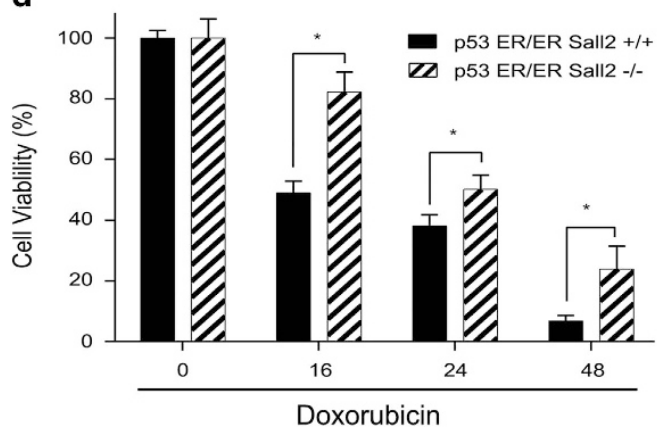

b

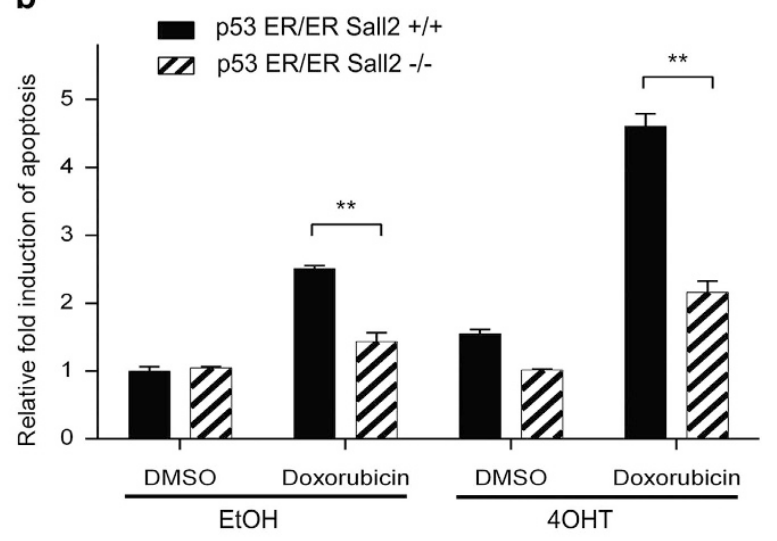

p53 ER/ER Sall2 -/-

\section{e}

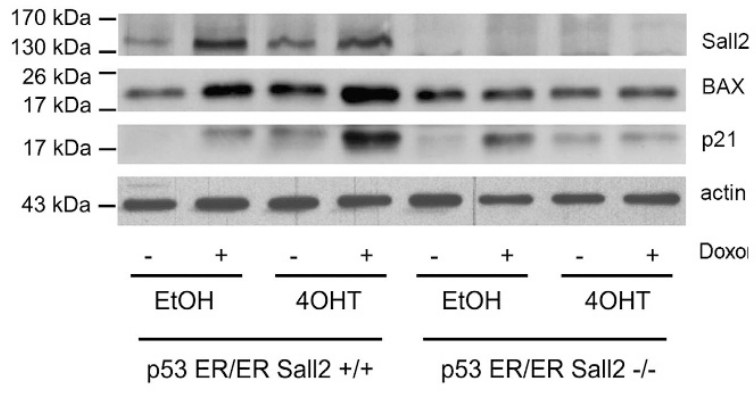

Figure 2 Sall2 expression is required for doxorubicin-induced apoptosis of primary MEFs. (a) MEFs Sall2 ${ }^{+/+}$(wild-type (WT)) and Sall2 ${ }^{-/-}$(null F1 and 15) were exposed to $1 \mu \mathrm{M}$ Doxorubicin or vehicle (DMSO) for $16 \mathrm{~h}$. Cellular apoptosis was measured by using a caspase-3/7 glow assay. Values are plotted as the mean \pm S.D. of quintuplicate exposures to drug or vehicle from three independent experiments. Relative fold induction of apoptosis was normalized to caspase-3/7 activity of Sall ${ }^{+/+}$MEFs exposed to DMSO ( ${ }^{* *} P<0.001$ ). (b) $p 53^{E R / E R} ;$ Sall $2^{+/+}$and $p 53^{E R / E R}$; Sall ${ }^{-/}$MEFs treated with $4-\mathrm{OHT} 100 \mathrm{nM}$ for $4 \mathrm{~h}$ (for functional p53) and then exposed to $1 \mu \mathrm{M}$ doxorubicin or vehicle (DMSO) for $16 \mathrm{~h}$. Apoptosis was measured as in (a). A significant difference in doxorubicin-dependent apoptosis between Sall $2^{++}$and Sall2 ${ }^{-/-}$MEFs was noted in the absence (EtOH) and presence (4-OHT) of functional p53 $\left.{ }^{* *} P<0.001\right)$. (c) $p 53^{E R E R}$; Sall ${ }^{+/+}$and Sall $2^{--}$MEFs were treated for $4 \mathrm{~h}$ with $4-\mathrm{OHT}$ and then exposed to $1 \mu \mathrm{M}$ doxorubicin. Cell lysates were collected at various times and levels of total p53 (detected as p53ER fusion protein), cleaved caspase-3 and cleaved PARP were analyzed by western blot. Actin shows equal loading. (d) $p 53^{E R / E R}$; Sall $2^{+/+}$ and $p 53^{\text {ERER }}$; Sall2 $2^{--}$MEFs treated for $4 \mathrm{~h}$ with $4-\mathrm{OHT} 100 \mathrm{nM}$ and then exposed to $1 \mu \mathrm{M}$ doxorubicin or vehicle (DMSO) for 16,24 and $48 \mathrm{~h}$. Cellular viability was measured using a CytoTox-Glo kit assay. Cell viability $(\%)$ is plotted as the mean \pm S.D. of two independent experiments performed in triplicate. Results are expressed as the percentage of survival relative to control (0- $\mathrm{h}$ time point). A significant difference in doxorubicin-dependent cellular viability between Sall2 ${ }^{+/+}$and Sall2 ${ }^{-/-}$MEFs was noted at each time evaluated (16, 24 and $48 \mathrm{~h}$, ${ }^{*} P<0.05$ ). (e) $p 53^{E R E R}$; Sall $2^{++}$and $p 53^{E R E R}$; Sall $2^{--}$MEFs were treated for $4 \mathrm{~h}$ with $4-\mathrm{OHT} 100 \mathrm{nM}$ or EtOH and then exposed to $1 \mu \mathrm{M}$ doxorubicin for $16 \mathrm{~h}$. Western blot evaluated levels of Sall2, BAX and p21. Actin shows equal loading. Figures are representative of three independent experiments

To confirm a Sall2-dependent transcriptional regulation of Noxa under genotoxic stress in MEFs, we analyzed Noxa mRNA levels by qPCR during different times of doxorubicin treatment, and compared them between Sall2 ${ }^{+/+}$and Sall2 $2^{-/}$ MEFs. After $8 \mathrm{~h}$ of treatment, Noxa mRNA significantly increased in Sall ${ }^{+/+}$MEFs and continued increasing up to $16 \mathrm{~h}$. In contrast, Noxa mRNA levels were modestly increased in Sall $2^{-1-}$ MEFs (Figure 3b). The difference of Noxa mRNA induction between Sall $2^{+/+}$and Sall2 $2^{-/}$MEFs was highly significant and was even more pronounced compared with that of $B A X$ mRNA (Figure $3 c$ ). These results confirm that there is a Sall2-dependent regulation of Noxa and BAX during doxorubicin treatment.

A consensus sequence, GGG (T/C) GGG, for optimal binding of Sall2 was identified previously. ${ }^{20}$ We searched for putative Sall2-binding sites in several apoptotic-related genes 
including members of the BH3-only, the proapoptotic BAX-like and the antiapoptotic $\mathrm{Bcl}-2$ protein subfamilies (Supplementary Figure 2). Based on the number of Sall2 putative sites present in the promoter, the proximity between the sites, the conservation between human and mouse promoter regions and the correlation between Noxa and Sall2 expression (Figures $3 a$ and b), we investigated Noxa. Bioinformatic analysis identified three putative Sall2-binding sites in the human NOXA/PMAIP1 (phorbol-12-myristate-13acetate-induced protein 1) gene (ID 5366) at positions - 77, -89 and -101 upstream of the transcription start site (represented as ovals in Figure 3d) (for latter studies named as h1, h2 and h3, respectively). Two putative Sall2-binding sites were also identified in the mouse Noxa/Pmaip1 gene (ID 58801 ) at positions -65 and -77 of start site (for latter studies named as $\mathrm{m} 1$ and $\mathrm{m} 2$, respectively). Responsiveness of human NOXA/PMAIP1 promoter - 198/+45 region to Sall2 was studied using a reporter described previously. ${ }^{43}$ HEK293 cells were co-transfected with pGL3-NOXA-N1 reporter and the mouse Sall2 isoform E1A (Sall2-GFP), or empty vector. Figure $3 e$ shows that expression of Sall2 significantly increased NOXA promoter activity. In addition to the human promoter, we cloned the $-970 /+325$ region of mouse promoter to test its regulation by Sall2. Similarly, we observed an increase in Noxa promoter activity in response to increasing concentrations of Sall2 protein, with a significant increase when using 1 and $2 \mu \mathrm{g}$ of Sall2 vector (Figure 3f). Nuclear localization and concentration-dependent increase of exogenous Sall2 expression were confirmed by immunofluorescence microscopy (Supplementary Figure 3).

We also evaluated whether Sall2 mediates Noxa transcriptional activity independently of p53 using human cancer cells that lack p53. We co-transfected the mouse Noxa promoter reporter with increasing concentrations of Sall2 in H1299 (p53-null) lung cancer cells. Figure $3 \mathrm{~g}$ shows that Sall2, in the absence of p53, also increased Noxa promoter activity in a concentration-dependent manner. Transfection of wild-type p53 increased Noxa promoter activity threefold compared with the eightfold increase by Sall2 (Figure 3h). When Sall2 and p53 were added together, they increased Noxa promoter activity more than 16-fold. Similar results were obtained by using HCT116 (p53-null) colon cancer cells (Supplementary Figure 4). Taken together, our data suggest that the increase on Sall2 expression positively regulates human and mouse Noxa gene expression, an effect that occurs in a p53independent manner. However, similar to the regulation of the $p 21^{\text {WAF }}$ promoter, ${ }^{12}$ our data also suggest that Sall2 and p53 synergizes to induce Noxa expression.

Sall2 binds to sequences located in the proximal promoter of the Noxa gene. Figure 4 a shows a sequence alignment of human and mouse Noxa proximal promoters, highlighting the putative Sall2 cognate sequences identified in our search (h1, h2, h3, m1 and m2). The spacing between sites 1 and 2 in the human and mouse promoters is the same (5 bp), and these sites are at a similar distance from the transcription start site in both species. We tested the ability of Sall2 to bind these sites using electrophoretic mobility shift assays (EMSA). We first used recombinant His-Sall2, expressed in Escherichia coli and then affinity purified
(Supplementary Figures 5A and B). We analyzed the binding of His-Sall2 to four different double-stranded oligonucleotide probes containing two or three putative Sall2-binding sites (Supplementary Data 1). As a control, we used a probe containing two copies of the Sall2-binding sequence described by $\mathrm{Gu}$ et $a l^{20}$ Sall2 binding to a probe containing two recognition sites was significantly stronger compared with a probe containing only one site (Supplementary Figure $5 \mathrm{C}$ ). Single retardation bands were obtained by incubating any of the oligonucleotide probes with His-Sall2 (Figure 4b). Similar binding strengths were obtained when comparing the control probe to the probes containing sites 1 and 2 of the human or mouse NOXA gene promoter (Figure 4b, compare lane 2 to lanes 4 and 6). A weaker affinity of His-Sall2 to probes harboring sites 2 and 3 of the human NOXA promoter was observed (Figure 4b, compare lanes 2, 4 and 6 to lane 8). The three Sall2-binding sites found in the proximal promoter of the human NOXA gene display the same core sequence (GGGCGGG). This fact suggests that the weaker affinity of Sall2 to probes containing site h3 relies on DNA sequences surrounding these Sall2-binding sites. His-Sall2 binds specifically to the sites contained in the probes tested, as demonstrated by competition analyses (Figure 4c, lanes 3, 4, 5, 9 and 10). Additionally, a supershift band was obtained when using an anti-His antibody, confirming that the retardation bands were generated by His-Sall2 (Figure 4c, lanes 6 and 11).

Subsequently, we performed EMSA analyses using nuclear extracts obtained from HEK293 cells transfected with a vector coding for Sall2-GFP. The expression of Sall2 was assessed by western blot analyses (Figure 5a). Non-detectable levels of endogenous Sall2 were observed when using an anti-Sall2 antibody (Figure 5a; no transfection: NT). We observed a strong binding to the probes harboring the mouse or human NOXA promoter, sites 1 and 2 (Figure $5 b$, lanes 7 and 11). The retardation band is generated by Sall2-GFP in the nuclear extracts as a supershift is observed when adding an anti-GFP antibody (Supplementary Figure 6A), and reactions using nuclear extracts from non-transfected cells did not result in the generation of these bands (Supplementary Figure 6B, lanes 2, 5 and 8 ). Competition analyses confirmed the specificity of this binding (Figure 5b, lanes 8, 9, 12 and 13). Minor faster and slower migrating bands were also observed using the nuclear extracts containing Sall2-GFP (Figure 5b, lanes 2, 7 and 11). The faster migrating bands were also observed when using nuclear extracts from non-transfected cells (Supplementary Figure 6B), suggesting the presence of other proteins with affinity for GC-rich sequences in these cells. The slower migrating band appears only with the use of Sall2-GFPcontaining nuclear extracts. It might reflect Sall2-GFP interaction with other nuclear proteins, the presence of posttranslational modifications in a subset of Sall2-GFP or interaction of an additional unit of Sall2-GFP. Taken together, our EMSA analyses indicate that the stimulatory effect of Sall2 in the reporter assays corresponds to a direct effect exerted by this transcription factor.

Sall2 interacts in vivo with a specific region of NOXA promoter. To demonstrate in vivo the interaction of Sall2 with NOXA promoter, we performed chromatin 
immunoprecipitation (ChIP) assays on HEK293 cells using a recently characterized Sall2 antibody. ${ }^{4}$ Cells were treated with doxorubicin for various times, chromatin was immunoprecipitated and specific genomic regions were analyzed by qPCR. Figure $6 a$ shows a representation of the NOXA promoter and the chromatin regions evaluated by amplification. Consistent with all our previous data, Sall2 significantly increased in vivo its binding to the Noxa promoter region containing the Sall2-specific binding sites during doxorubicin treatment (Figure 6b). In contrast, no binding of Sall2 was observed to a promoter region upstream of the Sall2-specific binding sites (Figure 6c). The increment of Sall2 binding was correlated with an increase in histone $\mathrm{H} 4$ acetylation, a transcriptional activation marker (Figure 6d). Of note, an effective binding after doxorubicin treatment was found for a previously defined region of the BAX promoter, ${ }^{20}$ which served as a positive control (Figure 6e). However, Sall2 binding to $B A X$ promoter was less pronounced compared with that observed for the Noxa promoter (2.0-versus 6.0-fold enhancement, respectively).

Doxorubicin-dependent Sall2/Noxa axis in Jurkat cells. To demonstrate the relevance of the Sall2/Noxa axis in a human cancer cell model, we used Jurkat leukemia $\mathrm{T}$ cell. Because these cells are null for $\mathrm{p53}$ and BAX, ${ }^{44-46}$ they allow us to investigate the role of Sall2 in cell death, in a p53- and a

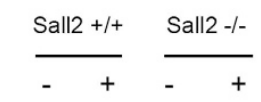

doxorubicin

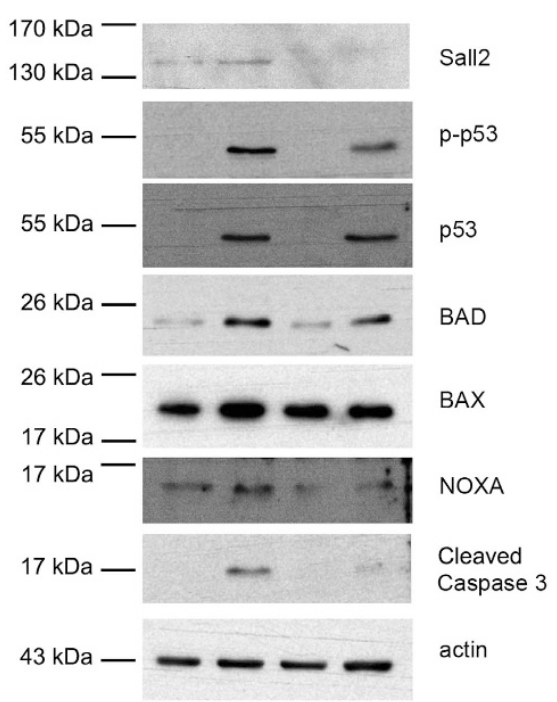

b

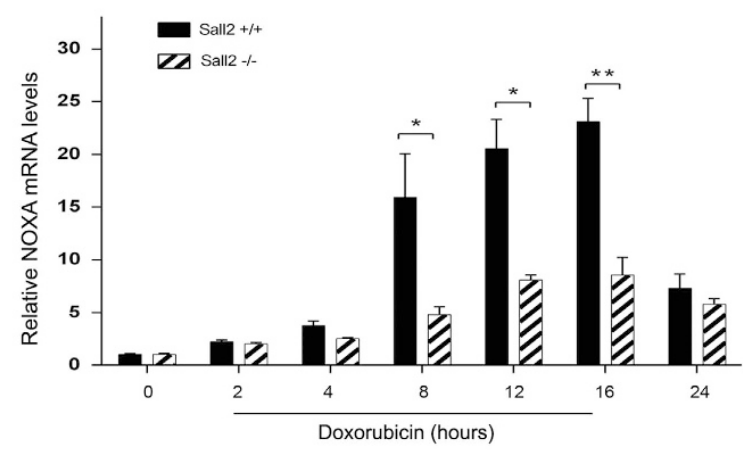

C

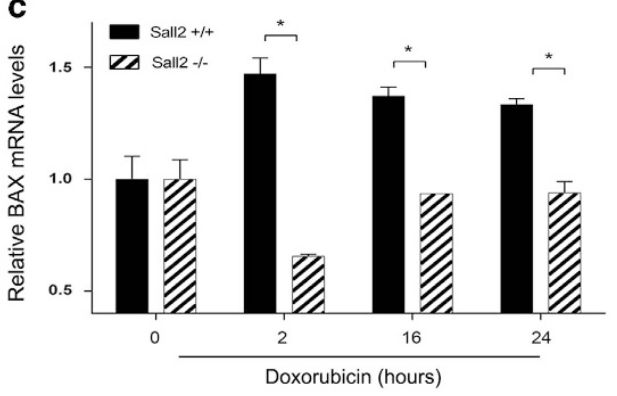

d

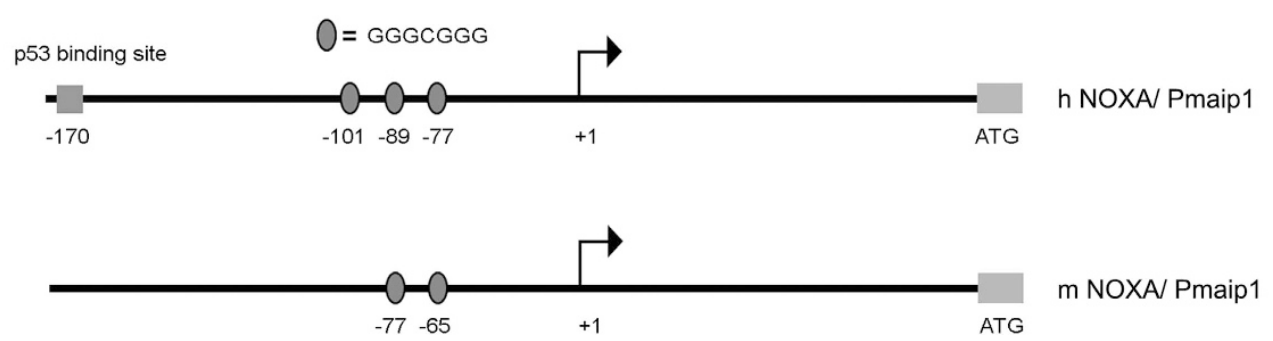

Figure 3 Sall2 expression correlates with induction of apoptotic markers, and increases NOXA promoter activity. (a) MEFs Sall $2^{+/+}$and Sall2 ${ }^{-/}$were exposed to $1 \mu \mathrm{M}$ doxorubicin or vehicle (DMSO) for $16 \mathrm{~h}$. Levels of Sall2, p-p53 (Ser18), p53, BAD, BAX, NOXA and cleaved caspase-3 were evaluated by western blot. Actin shows equal loading. The figure is representative of three independent experiments. ( $b$ and $\mathbf{c}$ ) MEFs Sall ${ }^{+/+}$and Sall2 $2^{-/-}$were exposed to $1 \mu \mathrm{M}$ doxorubicin for various times. Noxa (a) and BAX (b) mRNA levels were measured by quantitative real-time PCR and is relative to cyclophilin $A$. Level at time 0 was defined as 1 . Average values from triplicate samples are shown as representative of three independent experiments. ${ }^{*} P<0.05$; ${ }^{\star *} P<0.005$. (d) Schematic representation of human (h) and mouse (m) Noxa promoters and the location of identified Sall2 putative binding sites (represented by ovals) relative to the transcription start site (+1). (e) Transient co-transfection of the hNOXA-N1 promoter without and with Sall2 vector in HEK293 cells was performed as described in the Materials and Methods section. $(\mathrm{f})$ Transient co-transfection of the mouse Noxa promoter without or with increasing concentrations of Sall2 vector in HEK293 cells. (g) Transient co-transfection of the mouse Noxa promoter without and with increasing concentrations of Sall2 vector in human H1299 (p53-null) cells. (h) Transient co-transfection of the mouse Noxa promoter with Sall2, p53 or both, in human H1299 (p53-null) cells as described in the Materials and Methods section. From (e) to (h), cell extracts were analyzed for luciferase activity and normalized to $\beta$-galactosidase activity. Promoter activity is expressed as relative luciferase activity to pGL3 empty vector. Results represent three independent experiments performed in triplicate. Error bars represent the mean \pm S.D. Statistical significance was determined by Student's $t$-test $\left({ }^{\star} P<0.05\right.$; $\left.{ }^{\star \star} P<0.001\right)$. For figure $(\mathrm{h}),{ }^{*} P<0.05$ relative to $\mathrm{pGL} 3$ alone and ${ }^{\#} P<0.05$ relative to Sall2 and $p 53$ together 


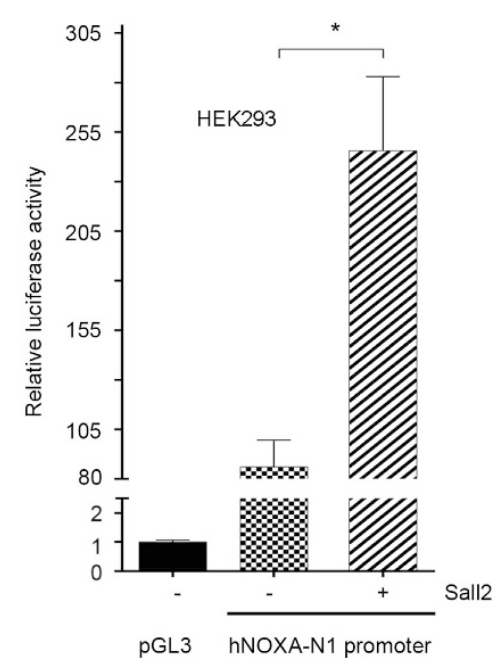

g

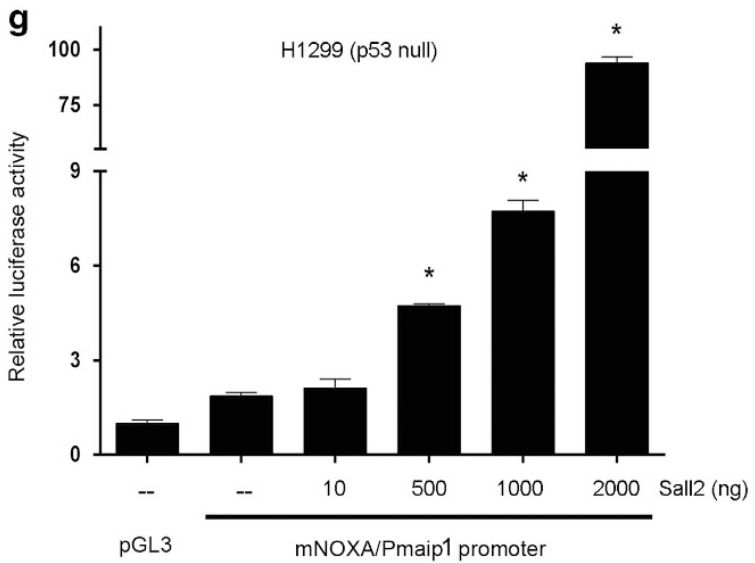

f

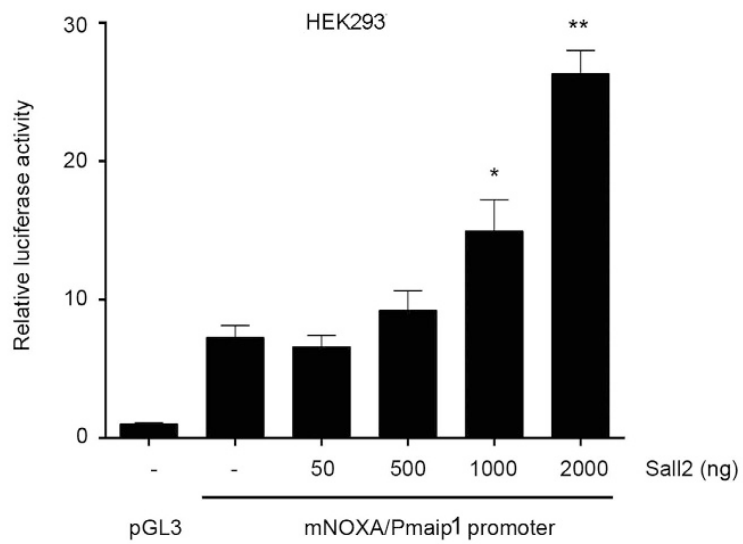

h

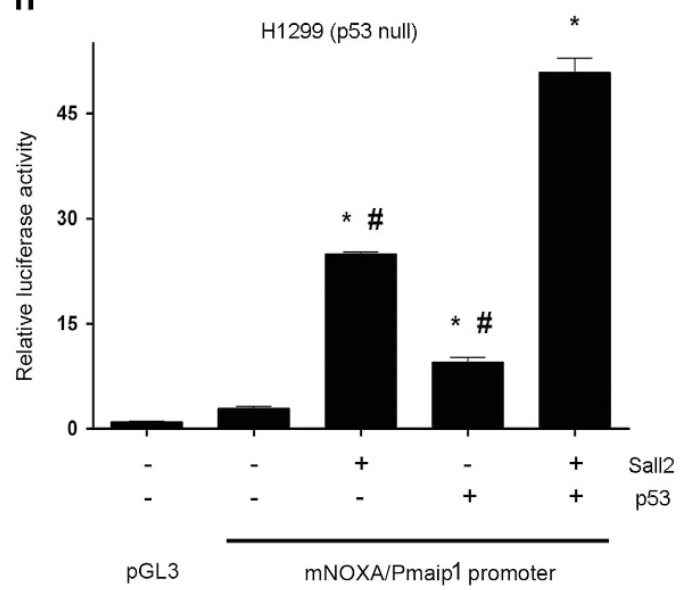

Figure 3 (Continued)

BAX-independent manner. In addition, it has previously been shown that in Jurkat cells Noxa is essential for genotoxic agent etoposide- ${ }^{46}$ and proteasome inhibitor bortezomib- 47,48 induced apoptosis, both drugs relevant for cancer treatments. Jurkat cells were treated with control or Sall2-specific siRNA and then exposed to doxorubicin for 24 and $32 \mathrm{~h}$. We used the 24- $\mathrm{h}$ time point for qPCR analysis to determine SALL2 and NOXA mRNA levels in response to doxorubicin, and the 32-h time point for western blot and functional assays. Figure 7a shows that SALL2 and NOXA mRNAs increased in response to doxorubicin (3.8- and 2.3-fold, respectively). Sall2 depletion by siRNA (Figure 7a, left panel) resulted in a significant decrease in NOXA mRNA induction (Figure 7a, right panel). Protein analysis confirmed the induction of Sall2 and Noxa (Figure 7b). However, the increase of Noxa protein was modest (1.9-fold) probably because of constitutive Noxa expression as reported previously, ${ }^{49}$ and/or a decrease in protein stability because incubating cells with a proteasome inhibitor, MG132 (carbobenzoxy-Leu-Leu-leucinal), increases Noxa protein levels (Supplementary Figure 7). We were unable to observe any increase in Noxa protein in response to doxorubicin in Sall2 siRNA-treated cells, which was correlated with a decrease in the levels of cleaved caspase-
3 (Figure 7b). As the latter result suggested a decrease in the apoptotic response, we also evaluated Sall2-dependent cell survival. Figure $7 \mathrm{c}$ shows that doxorubicin decreased cell survival by $50 \%$, and Sall 2 depletion partially, but significantly, reverted this effect. Finally, to confirm that Noxa is involved in the cell death response in this cancer cell model, cells were transfected with control or Noxa-specific siRNA and then treated with doxorubicin as above. Figure $7 \mathrm{~d}$ shows that Noxa depletion decreased the levels of cleaved caspase3 , which correlated with a significant increase on cell viability (Figure 7e). These results altogether indicate that in a p53and BAX-independent context Sall2 is needed for Noxa induction, a necessary step for full cell death response to doxorubicin in Jurkat cells.

\section{Discussion}

Increasing evidences indicate that alterations in the function of Sall2 have a role in disease, including cancer, ocular coloboma and kidney dysfunction. ${ }^{1-4}$ How Sall2 is involved in cancer is still controversial. Evidence have supported a role for Sall2 as a tumor suppressor. ${ }^{3,12,13,50}$ However, Sall2 is upregulated in various human cancers ${ }^{15-19,51}$ and is essential 
Mouse $\quad-140$ GGGGCGTCTCGA GACCTGCTCCACTTCGCTCGGTTCCCGCGCCGCCGCC--------GTT

Human -160 GCGGGGTACT TCCCCGCCCGCGTCCCGCGTCCGCTCCCATAACGCCGTCTGCGGGGCGGG

$\mathrm{m} 2$

m1

h3

Mouse -88CGAAGGGGCGGGGACACGGGCGGG------ATGTCGTCACAT GACGTCACCGGAGAAGTC

Human -100 GACAG $\frac{\overline{\text { GGGCGGG GACAGGGGCGGG }}}{\mathrm{h} 2}$ CC GGGCGTCTAGTTTCCC TACGTCACCAGGGAAGTT $+1$

Mouse $\quad-34$ CCGATAAAATGCGAGAGCCGGTCTGGGGCGCCTGAACAGAGAGGATTCCAGCGCTGGTGHuman $\quad-40$ CTCACTGGACAAAAGCGTG-GTCTCTGGCGCGGGGATCTCA GAgTTTCCCGGGCACTCAC $+1$

b

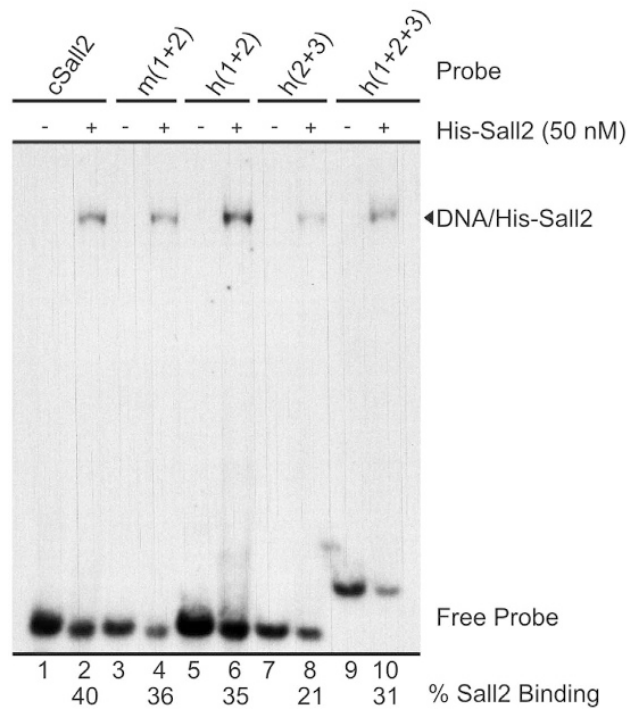

c

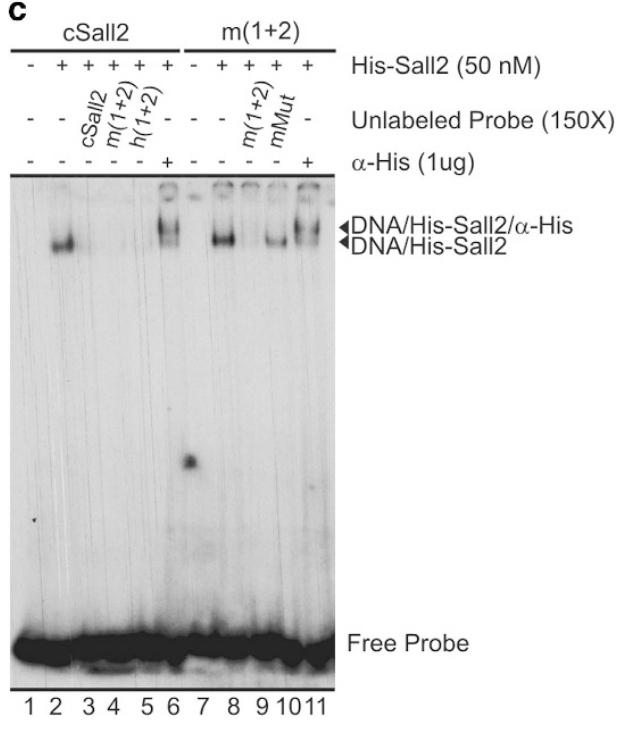

Figure 4 Analysis of Sall2-binding sites located at the Noxa gene in mouse and human promoters. (a) Sequence alignment of mouse and human Noxa promoter obtained from ClustalW. Underlined letters show Sall2-binding sites in both promoters, the putative sites are named h1, h2 and h3 (for human gene) or $\mathrm{m} 1$ and $\mathrm{m} 2$ (for mouse gene), and numbers denote the sites position from transcription start site. (b) EMSA assay testing double-stranded oligonucleotide probes containing the putative Sall2-binding sites located at mouse $(\mathrm{m} 1+2)$ and human $(\mathrm{h} 1+2, \mathrm{~h} 2+3$ and $\mathrm{h} 1+2+3)$ promoter region of NOXA/PMAIP1 gene, compared with consensus Sall2 double-binding site (cSall2), using recombinant His-Sall2 $(50 \mathrm{nM})$. The percentage of His-Sall2 binding is depicted at the bottom of the figure. The migration of free probe and the DNA/Sall2 complex are indicated at the right side of the figure. (c) The cSall2 and $\mathrm{m}(1+2)$ probes were used in a competition and supershift analysis with His-Sall2 $(50 \mathrm{nM})$. The competition was made in the presence of a $150 \times$ molar excess of the different unlabeled normal and mutant probe, as indicated at the top of the figure. The specificity of DNA/His-Sall 2 complex is corroborated by supershift using $1 \mu \mathrm{g}$ of His antibody. The migration of free probe, DNA/Sall2 and DNA/Sall2/ $\alpha$-His complexes is indicated at the right side of the figure

for glioblastoma propagation. ${ }^{4}$ These evidences suggest that the role of Sall2 is cell context-dependent. Thus, identification of Sall2 function and targets under different cell context are essential to understand its role in disease. We have recently demonstrated that p53 regulates Sall2 under genotoxic stress. ${ }^{27}$ Although the study could not provide a functional explanation for that regulation, here we demonstrated that Sall2 has an essential role in the apoptotic response to extended genotoxic stress. In support of this role, we identified the proapoptotic NOXA gene as a novel Sall2 target.

Our previous report suggested that Sall2 and p53 have opposite roles under genotoxic stress because Sall2 is negatively regulated by p53 under this condition. Here, analysis of Sall2 expression over the period of doxorubicin treatment demonstrated that Sall2 returns and increases after extended treatment, and localizes exclusively in the nucleus. Our results suggest that Sall2 and p53 rather cooperate in the apoptotic response. However, we also showed that the increase on Sall2 is independent of p53, and that Sall2 is relevant for apoptosis even in the absence of p53. Why Sall2 is downregulated at early times of genotoxic stress is unknown. p53 might initially downregulate Sall2 to support DNA repair and survival, but Sall2 is then necessary to cooperate with p53 to promote apoptosis if irreversible DNA damage occurred. In agreement, we found that Sall2 and p53 cooperate to activate the NOXA promoter. Similarly, independent and additive effects of Sall2 and p53 on the p21 WAF promoter have been reported, suggesting that Sall2 and p53 potentiate each other functions under certain cellular contexts. Consequently, loss of p53 and murine Sall2 synergistically promotes lymphomagenesis. ${ }^{13}$ Sall $2^{-/}$or Sall $2^{-/+} ; p 53^{-/-}$mice, compared with the Sall2 ${ }^{+/+} ; p 53^{-/}$mice, exhibit accelerated tumorigenesis and advanced tumor progression. ${ }^{13}$ All these results prompt further investigation to understand the regulatory and functional relationship between Sall2 and p53.

A role for Sall2 in apoptosis is in agreement with previous reports. Overexpression of Sall2 inhibits DNA synthesis and increases apoptosis of ovarian cancer cells, effects accompanied by increased expression of p21 WAF1 and BAX proteins. ${ }^{12}$ Consistently, Sall2 was found to directly regulate 


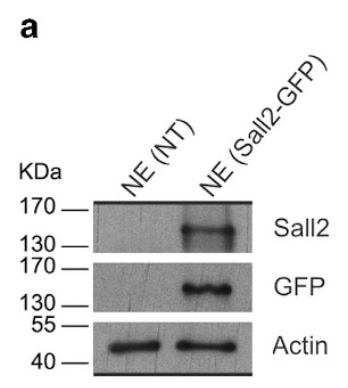

b

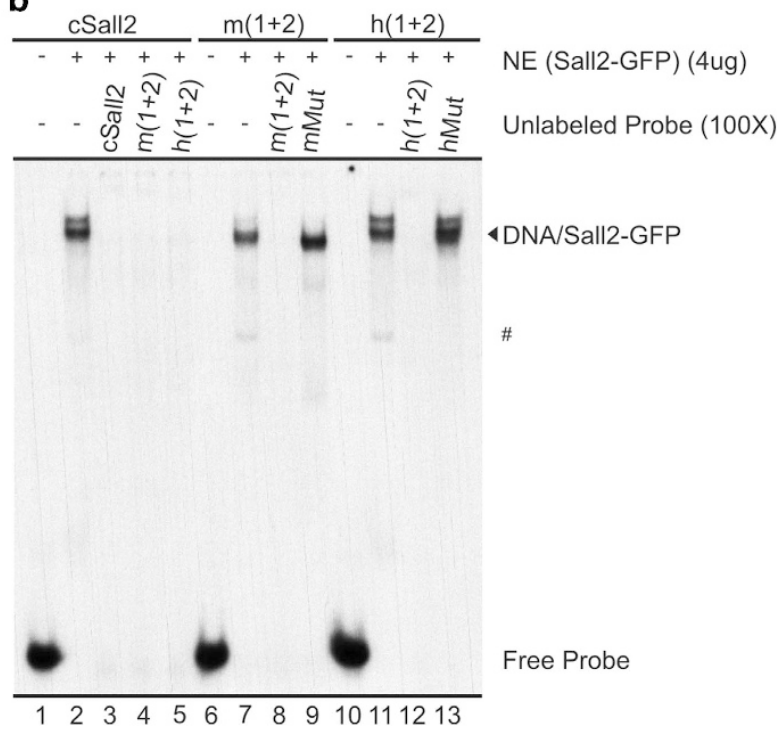

Figure 5 Sall2 specifically binds to a DNA sequence at the Noxa promoter. (a) Western blot analysis of nuclear extracts from HEK293 non-transfected (NT), or transfected with Sall2-GFP. Sall2 expression was confirmed using Sall2-specific (ATLAS) antibody, and anti-GFP antibody that recognizes Sall2-GFP fusion protein. $\beta$-Actin shows equal loading in each case. (b) The cSall2 and $\mathrm{m}(1+2)$, as well as $\mathrm{h}(1+2)$ probes, were used in a competition analysis using $4 \mu \mathrm{g}$ of nuclear extracts (NE, Sall2-GFP) in the presence of a $100 \times$ molar excess of the different unlabeled normal and mutant probe (three point mutations in each binding site), as indicated at the top of the figure. The competition was performed in the presence of a $100 \times$ molar excess of the different unlabeled normal and mutant probe, as indicated at the top of the figure. The migration of free probe and DNA/ Sall2-GFP complexes is indicated at the right side of the figure. "Corresponds to a faster migrating band (see comments in the text)

the proapoptotic $B A X$ after treatment of human ovarian surface epithelial (HOSE) cells with etoposide. ${ }^{20}$ In addition, treatment of HOSE cells with etoposide slightly increases both Sall2 levels and Sall2 binding to the $c-M y c$ promoter. $^{21}$ The latter was associated with $c-M y c$ repression and cellular apoptosis. However, Sall2 could have a prosurvival role during normal brain development. ${ }^{8}$ All these studies are consistent with a cell-context-dependent function for Sall2. Our results, in mouse embryonic fibroblast, reinforce $B A X$ as a conserved Sall2-dependent gene induced under genotoxic stress, and support that Sall2 is a stress-responsive molecule that promotes apoptosis under genotoxic stress.

Previous studies identified a consensus sequence for optimal binding of Sall2 in vitro, the sequence GGG (T/C) GGG was identified in human $B A X$ and $c-M y c$ gene promoters and the binding of Sall2 to these promoters was confirmed. ${ }^{20}$ Our studies confirmed that Noxa is a novel target for Sall2. Consequently, mRNA and protein analysis revealed that doxorubicin-dependent induction of Noxa was decreased in Sall2 ${ }^{-/}$MEFs, whereas induction of proapoptotic BAD was not affected by the lack of Sall2, suggesting a specific transcriptional regulation of apoptotic-related genes during genotoxic stress. The Sall2-dependent doxorubicin-induced Noxa expression was also confirmed in Jurkat $T$ leukemia cells, suggesting that the Sall2/Noxa axis happens in a cancer cell context.

Noxa is a central mediator of stress responses and critical for setting the apoptotic entrance. ${ }^{28,52}$ Noxa shows weak proapoptotic potential on its own, but is critical in fine-tuning cell death decisions because it targets for degradation $\mathrm{Mcl}-1$, a prosurvival protein. ${ }^{53,54}$ Noxa was initially defined as a p53-inducible gene in response to cellular stress. ${ }^{55,56}$ However, depending on the cell type and/or extension of a specific stress, Noxa can also be induced independently of p53 by other transcription factors, including p73, E2F1, HIF-1a, c-Myc, CREB and myocardin-related transcription factor $A .^{36,48,57-60}$ In response to etoposide- or doxorubicininduced DNA damage in MEFs, Noxa expression was shown to be strictly dependent on p53. ${ }^{36}$ This observation is apparently in disagreement with our observation that Sall2 is required for an efficient induction of Noxa by doxorubicin. A plausible explanation is that previous studies were carried out in a normal Sall2 context. Thus, together with our results, they indicate that Sall2 and p53 are required for the induction of Noxa. On the other hand, our studies in a cancer cell model, wherein p53 and BAX are absent, suggest that Sall2 is relevant for Noxa expression, and for the cell death response under genotoxic stress. However, we cannot conclude that only Noxa is responsible for the Sall2-dependent response to doxorubicin. Other factors, not yet identified, could be transcriptionally regulated by Sall2 and contribute to the apoptotic response. Studies in HOSE cells showed that Sall2 represses MYC under etoposide treatment, or when Sall2 is overexpressed. ${ }^{21}$ On the other hand, MYC is an activator of the NOXA gene upon proteasome inhibitor treatment in melanoma and HeLa cells. ${ }^{48}$ The relationship between c-Myc, Sall2, and Noxa is not straightforward because studies are from different cell types and context. Myc has both proliferation and apoptotic activities; these activities are context- and cell-dependent, but also threshold-dependent. ${ }^{61}$ Similarly, the Sall2 actions might depend on the cellular context, type of stress or threshold levels. To get a direct relationship, c-Myc, Sall2 and Noxa should be looked at in the same cell type, as the effect might be different from one cell to another. Further studies are needed to understand whether the requirement of Sall2 for the expression of Noxa and/or for 

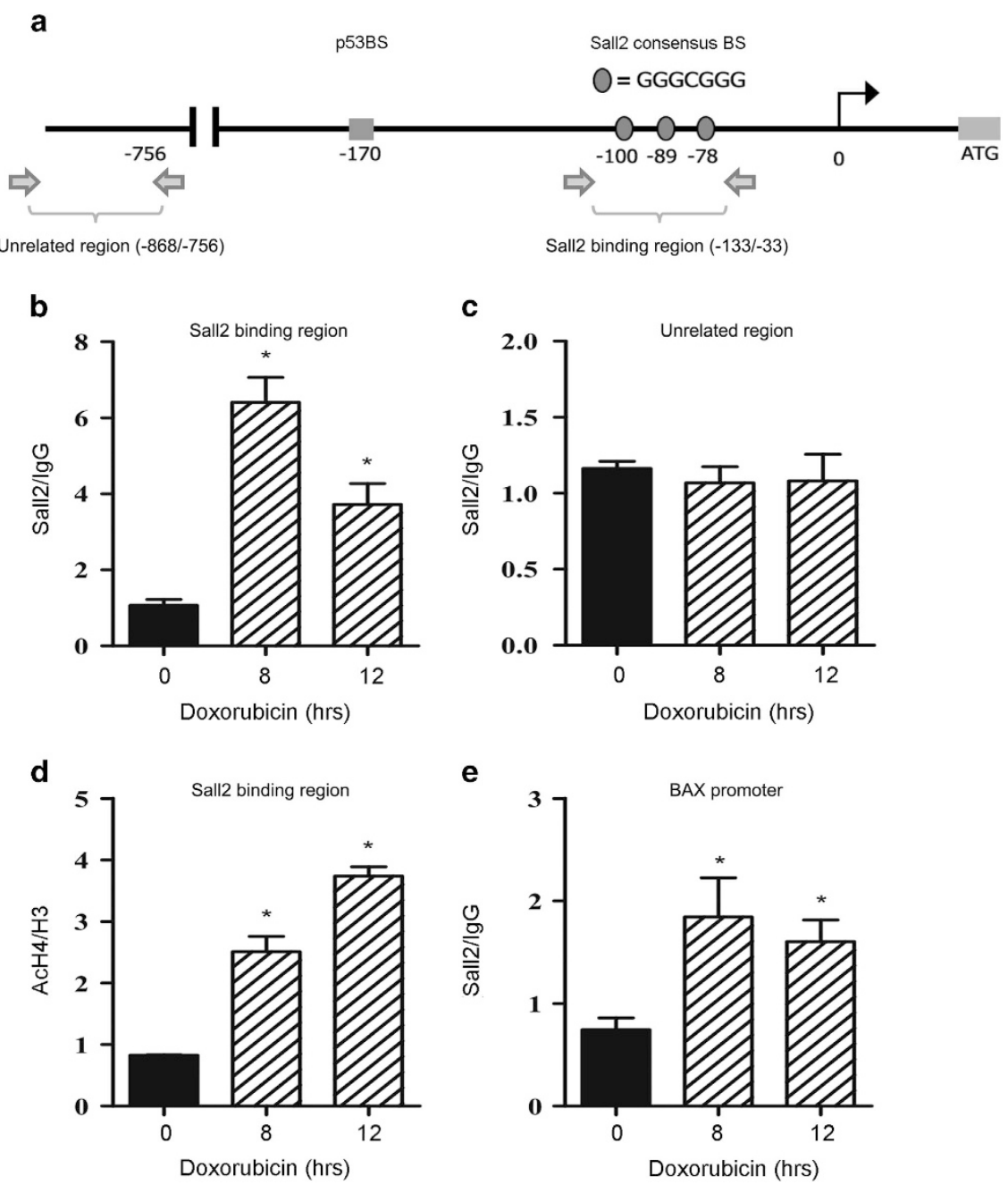

Figure 6 Sall2 interacts with NOXA promoter in vivo. (a) Schematic representation of the human NOXA promoter. Horizontal arrows indicate the location of primers used for qPCR in site-specific ChIP assays. Note that the figure is not drawn to scale. Black arrow: transcription start site. (b, c and e) HEK293 cells were treated with doxorubicin for 8 and $12 \mathrm{~h}$ and then anti-Sall2 antibody (Bethyl Lab) or normal rabbit IgG (control antibody) was used for ChIP. Real-time PCR was performed using primers that amplify the putative Sall2 region $(-133 /-33)(\mathbf{b})$, a nonspecific negative control region $(-868 /-756)$ where no binding is expected to occur (c) and the proximal region of the $B A X$ promoter used as a positive control for Sall2 binding ${ }^{20}$ (d). Changes in acetylation levels on nucleosomes located in the $(-133 /-33)$ region of the human NOXA promoter were measured by the ratio of acetylated $\mathrm{H} 4(\mathrm{AcH} 4)$ over total histone content $(\mathrm{H} 3)$. Graphs in $(\mathbf{b}, \mathbf{c}$ and $\mathbf{e})$ show quantification of the amplified DNA for each immunoprecipitation relative to lgG. Error bars represent 1S.D. for PCR reactions performed in triplicate from representative ChIP assay. Statistical significance was determined by Student's $t$-test ${ }^{*} P<0.05$ ). $\mathrm{BS}$, binding site

the apoptotic response is tissue-specific, or dependent on a specific stimulus within the same cell type, and how it relates with the levels of other transcription factors that could also regulate Noxa.

As most compounds used to treat cancer induce apoptosis, factors that influence apoptosis may contribute to the outcome of cancer therapy. Our study highlights the role of Sall2 in genotoxic stress-dependent apoptosis and the identification of the proapoptotic NOXA gene as a novel Sall2 target. We predict that future studies on the functional relationship between Sall2 and p53 will provide new avenues through our understanding of normal Sall2 function as well as its role during disease and treatments.

\section{Materials and Methods}

Reagents. Doxorubicin, 4-OHT, MG132, anti-actin and anti-Sall2 (HPA004162) antibodies were purchased from Sigma (St. Louis, MO, USA). Normal rabbit IgG, p21 monoclonal (H5) and GFP (B-2) antibodies were obtained from Santa Cruz Biotechnology (Santa Cruz, CA, USA). Anti-Bad (no. 9292), anti-Bax (no. 2772), anti-cleaved PARP (Asp214) (no. 9544), anti-cleaved caspase-3 (Asp175) (no. 9661) and anti-phosphorylated p53-Ser15 (no. 9284) were purchased from Cell Signaling Technology (Danvers, MA, USA). Anti-Sall2 antibody (no. A303-208) used for ChIP experiments was obtained from Bethyl Lab (Montgomery, TX, USA). $6 \times$ His monoclonal antibody (no. 631212) was obtained from Clontech (Mountain View, CA, USA). Anti-Noxa (no. 13654) was purchased from Abcam (Cambridge, UK). Anti-p53 (Pantropic PAb421; no. OP03) was obtained from Calbiochem (Billerica, MA, USA). Anti-histone $\mathrm{H} 3$ and anti-histone $\mathrm{H} 4$ acetylated were obtained from Millipore (Billerica, MA, USA). Control (no. 37007) and NOXA (no. 37305) siRNAs were obtained from Santa Cruz Biotechnology, and Sall2 (no. AM16708A) siRNA was from Ambion-Life Technologies Inc., Delegación Cuauhtémoc, Mexico DF, Mexico.

Plasmids. The human NOXA/PMAIP1 promoter (a gift from Yihong Ye, NIDDK, Bethesda, MD, USA) was described previously ${ }^{62}$ and was obtained from Addgene (Cambridge, MA, USA; plasmid no. 26112). The mouse Noxa/Pmaip1 promoter was cloned from genomic DNA from a wild-type mouse, using the following 
a

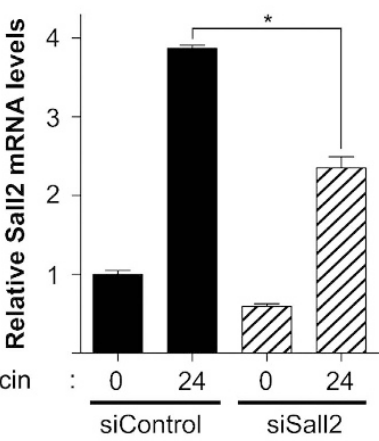

b

SiRNA:

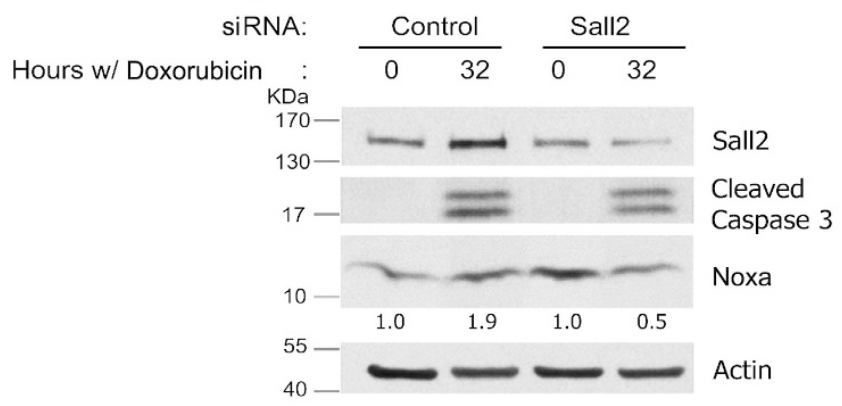

d

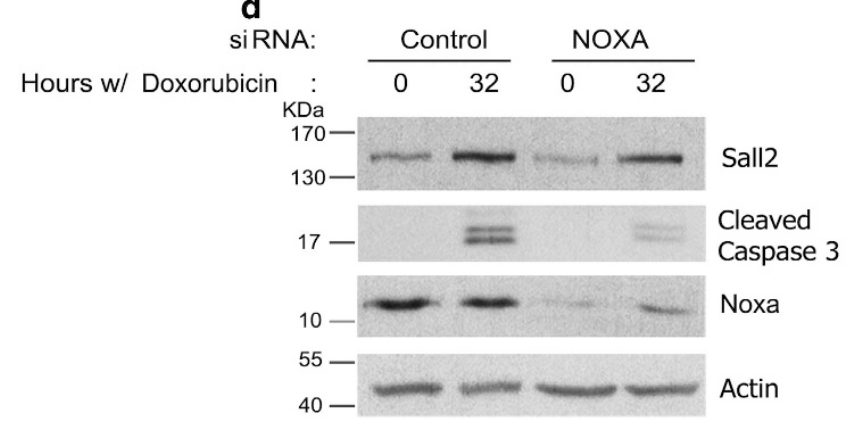

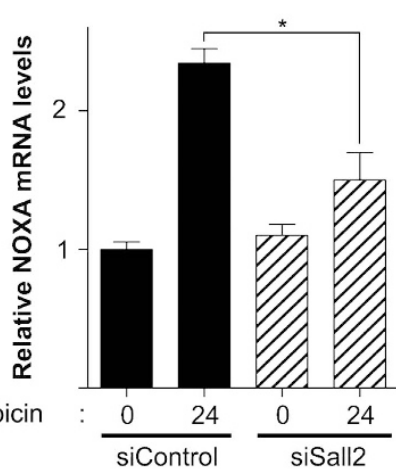

C

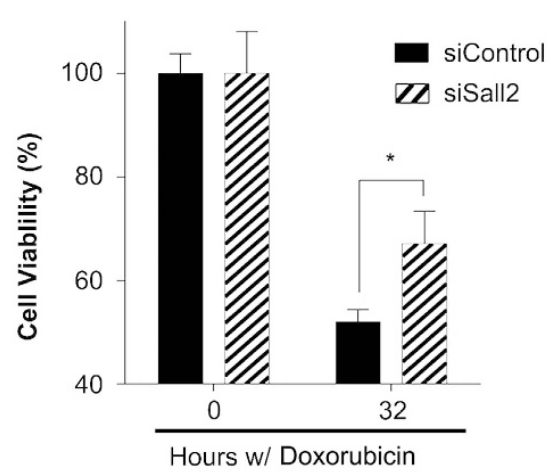

e

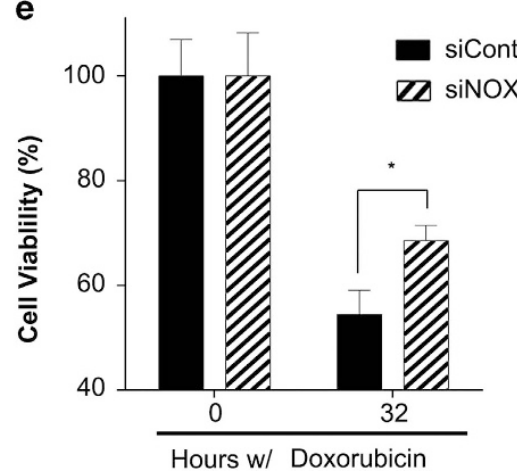

Figure 7 Doxorubicin-dependent Sall2/Noxa axis in Jurkat cells. Jurkat cells were transiently transfected with control or Sall2-specific small interfering RNA (siRNA). Cells were then treated with $0.5 \mu \mathrm{M}$ doxorubicin for 24 and $32 \mathrm{~h}$ to evaluate mRNA, proteins and cell survival. Sall2 (a, left) and Noxa (a, right) mRNA levels were evaluated after $24 \mathrm{~h}$. Doxorubicin treatment using quantitative real-time PCR. Expression of Sall2 and Noxa are relative to cyclophilin A, the expression at time 0 for siControl was defined as 1 . Values from triplicate samples are representative of two independent experiments. Each bar represents the mean \pm S.D. Statistical significance was determined by Student's $t$-test $\left({ }^{*} P<0.05\right)$. (b) Cell lysates were collected after $32 \mathrm{~h}$ to evaluate Sall2, cleaved caspase- 3 and Noxa proteins by western blot. The ratio of Noxa to actin was measured by densitometry and the fold increase of Noxa over that at time 0 was calculated (values are shown below Noxa western blot). Figure is representative of two independent experiments. (c) Cellular viability was measured after $32 \mathrm{~h}$ doxorubicin treatment using a CytoTox-Glo kit assay. The percentage (\%) of cell viability is plotted as the mean \pm S.D. of two independent experiments performed in triplicate. The percentage at time 0 for each siRNA was defined as $100 \%$. Statistical significance was determined by Student's $t$-test $\left({ }^{*} P<0.05\right)$. (d) Jurkat cells were transiently transfected with Control or Noxa siRNA and treated with doxorubicin as in (b). Cell lysates were collected and analyzed by western blot. Actin shows equal loading. (e) Jurkat cells were transiently transfected with Control or Noxa siRNA and treated with doxorubicin as in (b), and then cellular viability was measured as in (c). The percentage (\%) of cell viability is plotted as the mean \pm S.D. of two independent experiments performed in triplicate. The percentage at time 0 for each siRNA was defined as $100 \%$. Statistical significance was determined by student $t$-test $\left({ }^{*} P<0.05\right)$

oligonucleotides: forward, 5'-GTACAGATCTTTCACTTCAGAAGGGCGTTGCT-3' and reverse, 5'-AAACAAGCTTACATGCAGGCGCGTACATTCTA-3', and then the purified promoter was subcloned into the pGL3-Basic plasmid. The coding sequence for full-length mouse Sall2 was synthetized by GeneScrip (http://www. genscript.com/) according to the Sall2 codifying sequence published in the Sanger database (http://www.sanger.ac.u) and was designed in fusion with the C-terminal GFP tag. Mouse Sall2 sequence was then subcloned into pCDNA3 and pQE-80 L vectors. Fidelity of the mouse promoter and full-length Sall2 coding sequences were confirmed by sequencing analysis at Pontificia Universidad Católica Sequence Facility, Santiago, Chile. The pCMV-Neo-Bam p53 wild-type plasmid was a gift from Bert Vogelstein (Addgene; plasmid no. 16434). ${ }^{63}$

Cell culture. HEK293 human kidney epithelial cells (ATCC, Manassas, VA, USA; CRL-1573), HCT116 (p53-null) human colon cancer cells (a gift from Dr. 
Robert Warren, University of California San Francisco, San Francisco, CA, USA), Sall ${ }^{+/+}$, Sall $2^{-/}$and $p 53^{E R / E R}$ MEFs were cultured in Dulbecco's modified Eagle's medium (DMEM) (Hyclone, Logan, UT, USA) supplemented with 10\% (v/v) fetal bovine serum (FBS; Hyclone), $1 \%$ glutamine (Invitrogen Santa Fe, Mexico DF, Mexico) and 1\% penicillin/streptomycin (Invitrogen). H1299 (p53-null) human lung cancer cells (ATCC; CRL-5803) and Jurkat leukemia cells (a gift from Dr. Giancarlo de Ferrari, University Andres Bello, Santiago, Chile) were cultured in RPMI (Roswell Park Memorial Institute Medium) (Hyclone) supplemented with 10\% (v/v) FBS, $1 \%$ glutamine and $1 \%$ penicillin/streptomycin. Experiments with $p 53^{E R / E R} \mathrm{MEFs}$ and Sall $2^{-1}$ MEFs were performed with early passages (before passage 4). When indicated, it was added to the medium containing $100 \mathrm{nM}$ of $4-\mathrm{OHT}$ (Sigma) in $100 \% \mathrm{EtOH}$, or an equal volume of EtOH control. For genotoxic stress and p53 activation, doxorubicin was added to the cell culture at indicated concentrations and times (see figure legends).

Isolation of primary MEFs and genotyping. Sall2 knockout mice ${ }^{9}$ were obtained by collaboration with Dr. Ruichi Nishinakamura (Kumamoto University, Kumamoto, Japan; MTA (2010) to RP, Universidad de Concepción, Concepción, Chile). Similarly, the $p 53^{E R / E R}$ mice ${ }^{29}$ were obtained by a collaborative work with Dr. Gerard Evan (University of California San Francisco and University of Cambridge, Cambridge, UK). Sall $2^{+/-}$mice were crossed to generate isogenic Sall ${ }^{+/+}$and Sall $2^{-/}$embryos. Mice were group housed under standard conditions with food and water available ad libitum, and were maintained on a $12 \mathrm{~h} \mathrm{light/dark} \mathrm{cycle.} \mathrm{Mice}$ were fed a standard chow diet (Lab Diet, St Louis, MO, USA) containing no $<5 \%$ crude fat and were treated in compliance with the US National Institutes of Health guidelines for animal care and use. Studies were reviewed and approved by the Animal Ethics Committee of the Chile's National Commission for Scientific and Technological Research (CONICYT, protocol for project no. 1110821).

Fibroblasts from Sall $2^{+/+}$, Sall2 $2^{-/-}$, Sall $2^{+/+} ; p 53^{E R / E R}$ and Sall2 ${ }^{-/-} ; p 53^{E R / E R}$ were prepared from embryos at 13.5 days post coitum as described previously. ${ }^{9}$ Briefly, embryos, whose head and other red organs were removed, were smashed into pieces using a razor blade in a 10-cm dish with $5 \mathrm{ml}$ trypsin (Hyclone). The smashed embryo was incubated in trypsin for $15 \mathrm{~min}$ at $37^{\circ} \mathrm{C}$ followed by dilution in $10 \mathrm{ml}$ DMEM by pipetting up and down. The cells were centrifuged and seeded in 100-mm culture dishes (passage 0). MEFs were generated from independent embryos and routinely cultured as described above.

Mice were routinely genotyped by isolating tail DNA as reported previously. ${ }^{27}$ One microliter of genomic DNA was used for PCR analysis. Sall2 PCR was performed as described previously ${ }^{9}$ with the following oligonucleotides: forward, $5^{\prime}-\mathrm{CACA}$ TTTCGTGGGCTACAAG-3' and reverse, 5'-CTCAGAGCTGTTTTCCTGGG-3' and Neo, 5'-GCGTTGGCTACCCGTGATAT-3'. The sizes of the PCR products are $188 \mathrm{bp}$ for the wild-type mutant and $380 \mathrm{bp}$ for the null mutant. For the $p 53^{E R / E R}$ model, ${ }^{28}$ p53 genotyping ${ }^{29}$ was carried out with the following oligonucleotides: forward, 5'-CCTCCAGCCTAGAGCCTTCCAAGC-3' and reverse, 5'-GGTGAGATTTCATTGT AGGTGCC- $3^{\prime}$ and Neo, 5'-GCACACAAACTCTTCACCCTGC- $3^{\prime}$. The sizes of the $\mathrm{PCR}$ products are $430 \mathrm{bp}$ for the wild-type mutant and $700 \mathrm{bp}$ for the null mutant. All PCRs were performed for 32 cycles with annealing temperature for Sall 2 at $58^{\circ} \mathrm{C}$ and for p53 at $66^{\circ} \mathrm{C}$.

Western blot analysis. Proteins from cell lysates (50-70 $\mu \mathrm{g}$ of total protein) were fractionated by SDS-PAGE and transferred for $1 \mathrm{~h}$ at $200 \mathrm{~mA}$ to PVDF membrane (Immobilon; Millipore) using a wet transfer apparatus. The PVDF membranes were blocked for $2 \mathrm{~h}$ at room temperature in $5 \%$ nonfat milk in TBS-T (TBS with $0.1 \%$ Tween), and incubated with primary antibody at an appropriate dilution at $4{ }^{\circ} \mathrm{C}$ overnight in blocking buffer. After washing, the membranes were incubated with horseradish peroxidase-conjugated secondary antibodies diluted in TBS-T buffer for $30 \mathrm{~min}$ at room temperature. Immunolabeled proteins were visualized by ECL (Pierce, Thermo Scientific, Waltham, MA, USA).

Transient transfections and reporter gene assays. To evaluate Noxa promoter transcriptional activity, HEK293, H1299 (p53-nul) or HCT116 (p53-null) cells were transiently co-transfected with $0.75 \mu \mathrm{g}$ of NOXA-luc, $0.125 \mu \mathrm{g}$ of RSV- $\beta$ galactosidase ( $\beta$-Gal) and various concentrations of Sall2 or control vector per well. To evaluate the effect of Sall2 and p53 in Noxa promoter activity in H1299 and HCT116 (p53-null) cells, we used $2 \mu \mathrm{g}$ of each Sall2, p53 or both, and equivalent amount of vector control for comparative analysis. After $48 \mathrm{~h}$, the transfected cells were washed with phosphate-buffered saline, lysed with reporter assay lysis buffer (Promega, Madison, WI, USA) and spun at $14000 \times g$ to pellet cell debris. The supernatant was then assayed for luciferase and $\beta$-Gal activity using the manufacturer's suggested protocols (Promega). Luminescent reporter activity was measured using a Luminometer (Victor3; Perkin-Elmer). All transfections were normalized to $\beta$-Gal activity and performed in triplicate. Luciferase values were expressed as fold induction relative to the pGL3 vector control, or in some experiments to NOXA-luc. Statistical significance of $X$ versus $Y$-treated samples was determined by one-tailed Student's $t$-test.

Apoptosis and viability assays. For apoptosis assays in cell culture, we measured activation of caspase- 3 and -7 . Briefly, cells were seeded at $5 \times 10^{3}$ cells per 96-well plates. The next day, cells were incubated with $1 \mu \mathrm{M}$ doxorubicin for $16 \mathrm{~h}$ and analyzed for caspase- $3 / 7$ activities using as a substrate the tetrapeptide sequence DEVD fused to aminoluciferin (caspase-Glo 3/7 assay; Promega), according to the manufacturer's instructions. After caspase cleavage, aminoluciferin is released, producing luminescence from a coupled luciferase reaction. Luminescence was measured with a microplate luminometer (Victor3; Perkin-Elmer). All assays were performed in quintuplicate. For viability assays, we used CytoTox-Glo assay (Promega), which measures dead-cell protease activity using the luminogenic peptide AAF-Glo substrate. Briefly, cells were transfected (Jurkat) or not (MEFs), and seeded at $5 \times 10^{3}$ cells per 96 -well plates. The next day, cells were incubated with doxorubicin at concentrations and times indicated in figure legends. To determine cell viability, we first measured luminescence of dead cells and then, after adding the lysis buffer, we measured luminescence of the total cells. Cell viability was calculated subtracting the luminescence of dead cells to the total cells. Luminescence was measured with a microplate luminometer (Victor3; PerkinElmer). All assays were performed in triplicate.

Real-time quantitative reverse transcription-PCR. Total RNAs were extracted from cells with Trizol reagent (Life Technologies Inc.) according to the manufacturer's instructions. Before qPCR, the RNA was treated with Turbo DNase (Ambion) to eliminate any residual DNA from the preparation. One microgram of the total RNA was reverse transcribed using the Maloney murine leukemia virus reverse transcriptase (Invitrogen) and $0.25 \mu \mathrm{g}$ of Anchored Oligo(dT) 20 Primer (Invitrogen; 12577-011). qPCR was performed using KAPA SYBR FAST qPCR Master Mix Kit and the MX3000p Instrument (Stratagene, La Jolla, CA, USA) according to the manufacturer's instructions. The thermal cycling variables used were as follows: 40 cycles at $95^{\circ} \mathrm{C}$ for $5 \mathrm{~s}$ and $60^{\circ} \mathrm{C}$ for $20 \mathrm{~s}$. To control specificity of the amplified product, a melting-curve analysis was carried out. No amplification of unspecific product was observed. Amplification of cyclophilin $A$ was carried out for each sample as an endogenous control. Primer sequences were $5^{\prime}$-AGGAAGGAAGT TCCGCCG-3' (forward) and 5'-AGCGTTTCTCTCATCACATCACA-3' (reverse) for mouse Noxa, 5'-GATCTCCTCCGCAGTCTGG-3' (forward) and 5'-ACACAATGG GTATCCGGTCT-3' (reverse) for mouse Sall2, 5' GGAGCAGCTTGGGAGCG 3' (forward) and $5^{\prime}$ AAAAGGCCCCTGTCTTCATGA $3^{\prime}$ (reverse) for BAX and 5'-T TGTGGCCTTAGCTACAGGA-3' (forward) and 5'-GCTCACCGTAGATGCTCTTT-3' (reverse) for mouse and human Cyclophilin A, 5'-GCACTCGGAGACAGATGACA-3' (forward) and 5'-CGCTTCCCCTATGTGCTAGA-3' (reverse) for human SALL2, and 5'-CAGAGCTGGAAGTCGAGTGT-3' (forward) and 5'-AGGAGTCCCCTCATGC AAGT-3' (reverse) for human NOXA. The relative expression ratio of the NOXA and SALL2 genes was calculated using the standard curve method, using untreated (vehicle) cells as reference. Expression of Sall2, Noxa and BAX were relative to cyclophilin A.

Recombinant protein, nuclear extracts and EMSA. Recombinant Sall2 protein was purified as an N-terminal His-tag fusion protein using Ni-NTA agarose resin (cat. no. 30210; Qiagen, Hilden, Germany), according to the manufacturer's instructions. The protein stocks were concentrated using Amicon Ultra-4 $100 \mathrm{kDa}$ (Millipore). The quality of purified His-Sall2 was confirmed by Coomassie staining and by western blot using anti-His and anti-Sall2 antibodies. Nuclear extracts were obtained from HEK293 cells, transiently transfected with a vector coding for Sall2-GFP. The extracts were obtained according to the Dignam method ${ }^{64}$ and the presence of Sall2-GFP was confirmed by western blot. EMSAs were performed using $100 \mathrm{ng}(50 \mathrm{nM})$ of purified His-Sall2 or $4 \mu \mathrm{g}$ of nuclear extract. Twenty femtomoles of ${ }^{32} \mathrm{P}$-end-labeled oligonucleotide probes were used separately in a $20 \mu \mathrm{l}$ total binding reaction volume (see sequence information in Supplementary Data 1), including $100 \mathrm{ng}$ of pBluescript DNA (Hinfl-digested). Binding reactions were adjusted to the following final conditions: $10 \mathrm{mM} \mathrm{HEPES}(\mathrm{pH}$ 7.5), $100 \mathrm{mM} \mathrm{KCl}, 3 \mathrm{mM}$ DTT, $0.05 \%$ NP-40, 3\% glycerol, $5 \mu \mathrm{g} / \mathrm{ml} \mathrm{BSA}, 2.5 \mathrm{mM}$ $\mathrm{MgCl}_{2}$ and $5 \mu \mathrm{M} \mathrm{ZnCl}_{2}$. The reactions were incubated for $30 \mathrm{~min}$ at $30^{\circ} \mathrm{C}$ and then the samples were subjected to electrophoresis in a non-denaturing polyacrylamide 
gel $(5 \%$ (w/v); acrylamide : bis-acrylamide ratio $60: 1 ; 0.3 \times \mathrm{TBE})$ at $200 \mathrm{~V}$. Later, gels were dried and subjected to autoradiography. Supershift analyses were carried out by incubating His-Sall2 with a His antibody for $30 \mathrm{~min}$ at $4^{\circ} \mathrm{C}$, before proceeding with the EMSA binding reaction.

ChIP assay. ChIP assay was carried out as described previously ${ }^{65}$ with the following modifications: HEK293 cells were grown on $100-\mathrm{mm}$ dishes to $80 \%$ confluency and then treated with $5 \mu \mathrm{M}$ of doxorubicin for 0,8 and $12 \mathrm{~h}$. Cell nuclei were sonicated to shear DNA in $300 \mu \mathrm{l}$ of sonication buffer, using a Misonix sonicator (model 3000) (18 times, $15 \mathrm{~s}$ on/20 s off each time, 6-9 W potency), obtaining lengths between 300 and $600 \mathrm{bp}$. Immunoprecipitations were carried out overnight at $4^{\circ} \mathrm{C}$ using $5 \mu \mathrm{g}$ of Sall2 (anti-Sall2; Bethyl Lab), $1 \mu \mathrm{g}$ of $\mathrm{H} 3$ (antihistone $\mathrm{H} 3$; Upstate), $1 \mu \mathrm{g}$ of acH4 (anti-histone $\mathrm{H} 4$ acetylated; Upstate) or $5 \mu \mathrm{g}$ normal rabbit IgG antibodies (Santa Cruz) and $40 \mu \mathrm{g}$ of chromatin. DNA was analyzed by real-time PCR directed to NOXA/Pmaip1 promoter Sall2-specific regions $(-133 /-33)$, and the region $(-868 /-756)$ served as a negative control of Sall2 binding. The BAX promoter region $(-183 /+70)$ was used as a positive control for Sall2 binding. ${ }^{20}$ All the primers used are summarized in Supplementary Data 1. All PCR reactions (KAPA SYBR FAST qPCR; Kappa Biosystems, Wilmington, MA, USA) contained $1 \mu \mathrm{l}$ of input and $3 \mu \mathrm{l}$ of IP samples. Real-time PCR data were analyzed using the standard curve method.

\section{Conflict of Interest}

The authors declare no conflict of interest.

Acknowledgements. We thank Roberto Riquelme, Daniela Andrade and Fanya Rostker for animal technical support. We thank Dr. Giancarlo de Ferrari (Universidad Andres Bello) for providing us Jurkat cells, and Dr. Soraya Gutierrez (Universidad de Concepción) for anti-AcH4 antibody. This work was supported by Regular Fondecyt Grants 1110821 and 1151031-Chile (to RP) and DIUC grant from Universidad de Concepción from Chile (to RP). Additional funding was from Regular Fondecyt Grant 1120923-Chile (to AC) and Enlace-VRID 212.037.017-1.0 Grant-Universidad de Concepción (to JLG, AC and RP). DE and TC were supported by $\mathrm{PhD}$ fellowships from CONICYT-Chile. CF and MM were supported by the Regular Fondecyt Grant 1110821-Chile (to RP).

1. Chatterjee R, Hoffman M, Cliften P, Seshan S, Liapis H, Jain S. Targeted exome sequencing integrated with clinicopathological information reveals novel and rare mutations in atypical, suspected and unknown cases of Alport syndrome or proteinuria. PLOS One 2013; 8 : e76360.

2. Kelberman D, Islam L, Lakowski J, Bacchelli C, Chanudet E, Lescai $F$ et al. Mutation of SALL2 causes recessive ocular coloboma in humans and mice. Hum Mol Genet 2014; 23 . 2511-2526.

3. Sung CK, Li D, Andrews E, Drapkin R, Benjamin T. Promoter methylation of the SALL2 tumor suppressor gene in ovarian cancers. Mol Oncol 2013; 7: 419-427.

4. Suva ML, Rheinbay E, Gillespie SM, Patel AP, Wakimoto H, Rabkin SD et al. Reconstructing and reprogramming the tumor-propagating potential of glioblastoma stem-like cells. Cell 2014; 157: 580-594

5. de Celis JFaBR. Regulation and function of Spalt proteins during animal development Int J Dev Biol 2008; 52: 1-14.

6. Basson M, Horvitz HR. The Caenorhabditis elegans gene sem-4 controls neuronal and mesodermal cell development and encodes a zinc finger protein. Genes Dev 1996; 10 : 1953-1965.

7. Sweetman D, Munsterberg A. The vertebrate spalt genes in development and disease. Dev Biol 2006; 293: 285-293.

8. Bohm J, Buck A, Borozdin W, Mannan AU, Matysiak-Scholze U, Adham I et al. Sall1, sall2, and sall4 are required for neural tube closure in mice. Am J Pathol 2008; 173: 1455-1463.

9. Sato A, Matsumoto Y, Koide U, Kataoka Y, Yoshida N, Yokota T et al. Zinc finger protein sall2 is not essential for embryonic and kidney development. Mol Cell Biol 2003; 23: 62-69.

10. Liapis H. Renal Pathology: SC23-1 role of next generation sequencing (NGS) in the diagnosis of hereditary renal disease. Pathology 2014; 46: S39-S40.

11. Bandera CA, Takahashi H, Behbakht K, Liu PC, LiVolsi VA, Benjamin I et al. Deletion mapping of two potential chromosome 14 tumor suppressor gene loci in ovarian carcinoma. Cancer Res 1997: 57: 513-515.

12. Li D, Tian Y, Ma Y, Benjamin T. p150(Sal2) is a p53-independent regulator of p21(WAF1/CIP) Mol Cell Biol 2004; 24: 3885-3893.

13. Chai $\mathrm{L}$. The role of HSAL (SALL) genes in proliferation and differentiation in normal hematopoiesis and leukemogenesis. Transfusion 2011; 51: 87S-93S.

14. Alarcon-Vargas D, Ronai Z. P53-Mdm2 - the affair that never ends. Carcinogenesis 2002 23: $541-547$.
15. Nielsen TO, Hsu FD, O'Connell JX, Gilks CB, Sorensen PH, Linn S et al. Tissue microarray validation of epidermal growth factor receptor and SALL2 in synovial sarcoma with comparison to tumors of similar histology. Am J Pathol 2003; 163: 1449-1456.

16. Subramaniam MM, Navarro S, Pellin A, Lopez-Guerrero JA, Carda C, Heredia Alvaro JA et al. Tissue microarray profiling of primary and xenotransplanted synovial sarcomas demonstrates the immunophenotypic similarities existing between SYT-SSX fusion gene confirmed, biphasic, and monophasic fibrous variants. Virchows Arch 2006; 449: 435-447.

17. Braakhuis BJ, Brakenhoff RH, Leemans CR. Gene expression profiling in head and neck squamous cell carcinoma. Curr Opin Otolaryngol Head Neck Surg 18: 67-71.

18. Estilo CL, Oc P, Talbot S, Socci ND, Carlson DL, Ghossein R et al. Oral tongue cancer gene expression profiling: Identification of novel potential prognosticators by oligonucleotide microarray analysis. BMC Cancer 2009; 9: 11

19. Alagaratnam S, Lind GE, Kraggerud SM, Lothe RA, Skotheim RI. The testicular germ cell tumour transcriptome. Int J Androl 2011; 34: e133-e150; discussion e150-e131.

20. Gu H, Li D, Sung CK, Yim H, Troke P, Benjamin T. DNA-binding and regulatory properties of the transcription factor and putative tumor suppressor p150(Sal2). Biochim Biophys Acta 2011; 1809: 276-283

21. Sung CK, Yim H, Gu H, Li D, Andrews E, Duraisamy $\mathrm{S}$ et al. The polyoma virus large T binding protein p150 is a transcriptional repressor of c-MYC. PLoS One 2012; 7: e46486.

22. Beckerman R, Prives C. Transcriptional regulation by p53. Cold Spring Harbor Perspect Biol 2010; 2: a000935.

23. Vousden KH, Prives C. Blinded by the light: the growing complexity of p53. Cell 2009; 137: 413-431.

24. Meulmeester E, Jochemsen AG. P53: a guide to apoptosis. Curr Cancer Drug Targets 2008; 8: 87-97.

25. Speidel D. Transcription-independent p53 apoptosis: an alternative route to death. Trends Cell Biol 2010; 20: 14-24.

26. Zuckerman V, Wolyniec K, Sionov RV, Haupt S, Haupt Y. Tumour suppression by p53: the importance of apoptosis and cellular senescence. J Pathol 2009; 219: 3-15.

27. Farkas C, Martins CP, Escobar D, Hepp Ml, Castro AF, Evan G et al. Wild type p53 transcriptionally represses the SALL2 transcription factor under genotoxic stress. PLoS One 2013; 8: e73817.

28. Ploner $\mathrm{C}$, Kofler R, Villunger A. Noxa: at the tip of the balance between life and death. Oncogene 2008; 27: S84-S92.

29. Christophorou MA, Martin-Zanca D, Soucek L, Lawlor ER, Brown-Swigart L, Verschuren EW et al. Temporal dissection of p53 function in vitro and in vivo. Nat Genet 2005; 37: 718-726.

30. Garcia D, Warr MR, Martins CP, Brown Swigart L, Passegue E, Evan GI. Validation of MdmX as a therapeutic target for reactivating p53 in tumors. Genes Dev 2011; 25: 1746-1757.

31. Martins CP, Brown-Swigart L, Evan Gl. Modeling the therapeutic efficacy of $p 53$ restoration in tumors. Cell 2006; 127: 1323-1334.

32. Shchors K, Persson Al, Rostker F, Tihan T, Lyubynska N, Li N et al. Using a preclinical mouse model of high-grade astrocytoma to optimize p53 restoration therapy. Proc Natl Acad Sci USA 2013; 110: E1480-E1489.

33. Attardi LD, de Vries A, Jacks T. Activation of the p53-dependent G1 checkpoint response in mouse embryo fibroblasts depends on the specific DNA damage inducer. Oncogene 2004; 23: $973-980$

34. Attardi LD, Reczek EE, Cosmas C, Demicco EG, McCurrach ME, Lowe SW et al. PERP, an apoptosis-associated target of p53, is a novel member of the PMP-22/gas3 family. Genes Dev 2000; 14: 704-718.

35. Vousden $\mathrm{KH}$. Activation of the p53 tumor suppressor protein. Biochim Biophys Acta 2002; 1602: 47-59.

36. Shaposhnikov D, Descot A, Schilling J, Posern G. Myocardin-related transcription factor A regulates expression of Bok and Noxa and is involved in apoptotic signalling. Cell Cycle 2012; 11: 141-150.

37. Vousden KH, Lu X. Live or let die: the cell's response to p53. Nat Rev Cancer 2002; 2 : 594-604.

38. Park EJ, Kwon HK, Choi YM, Shin HJ, Choi S. Doxorubicin induces cytotoxicity through upregulation of pERK-dependent ATF3. PLoS One 2012; 7: e44990.

39. Peidis P, Papadakis Al, Muaddi H, Richard S, Koromilas AE. Doxorubicin bypasses the cytoprotective effects of elF2alpha phosphorylation and promotes PKR-mediated cell death. Cell Death Differ 2011; 18: 145-154.

40. Surma M, Handy C, Chang J, Kapur R, Wei L, Shi J. ROCK1 deficiency enhances protective effects of antioxidants against apoptosis and cell detachment. PLoS One 2014; 9: e90758.

41. Kamada S, Kikkawa U, Tsujimoto Y, Hunter T. Nuclear translocation of caspase-3 is dependent on its proteolytic activation and recognition of a substrate-like protein(s). J Biol Chem 2005; 280: 857-860

42. Woo M, Hakem R, Soengas MS, Duncan GS, Shahinian A, Kagi D et al. Essential contribution of caspase 3/CPP32 to apoptosis and its associated nuclear changes. Genes Dev 1998; 12: 806-819.

43. Wang B, Xiao Z, Ren EC. Redefining the p53 response element. Proc Natl Acad Sci USA 2009; 106: 14373-14378.

44. Brimmell M, Mendiola R, Mangion J, Packham G. BAX frameshift mutations in cell lines derived from human haemopoietic malignancies are associated with resistance to apoptosis and microsatellite instability. Oncogene 1998; 16: 1803-1812.

45. Cheng J, Haas M. Frequent mutations in the $\mathrm{p} 53$ tumor suppressor gene in human leukemia T-cell lines. Mol Cell Biol 1990; 10: 5502-5509. 
46. Karpinich NO, Tafani M, Schneider T, Russo MA, Farber JL. The course of etoposideinduced apoptosis in Jurkat cells lacking p53 and Bax. J Cell Physiol 2006; 208: 55-63.

47. Baou M, Kohlhaas SL, Butterworth M, Vogler M, Dinsdale D, Walewska R et al. Role of NOXA and its ubiquitination in proteasome inhibitor-induced apoptosis in chronic lymphocytic leukemia cells. Haematologica 2010; 95: 1510-1518.

48. Nikiforov MA, Riblett M, Tang WH, Gratchouck V, Zhuang D, Fernandez $Y$ et al. Tumor cellselective regulation of NOXA by c-MYC in response to proteasome inhibition. Proc Natl Acad Sci USA 2007; 104: 19488-19493.

49. Lowman $\mathrm{XH}$, McDonnell MA, Kosloske A, Odumade OA, Jenness $\mathrm{C}$, Karim $\mathrm{CB}$ et al. The proapoptotic function of Noxa in human leukemia cells is regulated by the kinase Cdk5 and by glucose. Mol cell 2010; 40: 823-833.

50. Li D, Dower K, Ma Y, Tian Y, Benjamin TL. A tumor host range selection procedure identifies p150(sal2) as a target of polyoma virus large T antigen. Proc Natl Acad Sci USA 2001; 98 : 14619-14624.

51. Li CM, Guo M, Borczuk A, Powell CA, Wei M, Thaker HM et al. Gene expression in Wilms' tumor mimics the earliest committed stage in the metanephric mesenchymal-epithelial transition. Am J Pathol 2002; 160: 2181-2190.

52. Willis SN, Adams JM. Life in the balance: how BH3-only proteins induce apoptosis. Curr Opin Cell Biol 2005; 17: 617-625.

53. Chen L, Willis SN, Wei A, Smith BJ, Fletcher JI, Hinds MG et al. Differential targeting of prosurvival Bcl-2 proteins by their BH3-only ligands allows complementary apoptotic function. Mol cell 2005; 17: 393-403.

54. Shibue T, Taniguchi T. BH3-only proteins: integrated control point of apoptosis. Int J Cancer 2006; 119: 2036-2043.

55. Oda E, Ohki R, Murasawa H, Nemoto J, Shibue T, Yamashita T et al. Noxa, a BH3-only member of the Bcl-2 family and candidate mediator of p53-induced apoptosis. Science 2000; 288: 1053-1058.

56. Shibue T, Takeda K, Oda E, Tanaka H, Murasawa H, Takaoka A et al. Integral role of Noxa in p53-mediated apoptotic response. Genes Dev 2003; 17: 2233-2238.

57. Grande L, Bretones G, Rosa-Garrido M, Garrido-Martin EM, Hernandez T, Fraile S et al. Transcription factors Sp1 and p73 control the expression of the proapoptotic protein NOXA in the response of testicular embryonal carcinoma cells to cisplatin. J Biol Chem 2012; 287: 26495-26505.
58. Hershko T, Ginsberg D. Up-regulation of Bcl-2 homology $3(\mathrm{BH} 3)$-only proteins by E2F1 mediates apoptosis. J Biol Chem 2004; 279: 8627-8634.

59. Kim JY, Ahn HJ, Ryu JH, Suk K, Park JH. BH3-only protein Noxa is a mediator of hypoxic cell death induced by hypoxia-inducible factor 1alpha. J Exp Med 2004; 199: 113-124.

60. Liu YL, Lai F, Wilmott JS, Yan XG, Liu XY, Luan Q et al. Noxa upregulation by oncogenic activation of MEK/ERK through CREB promotes autophagy in human melanoma cells Oncotarget 2014; 5: 11237-11251.

61. Murphy DJ, Junttila MR, Pouyet L, Karnezis A, Shchors K, Bui DA et al. Distinct thresholds govern Myc's biological output in vivo. Cancer Cell 2008; 14: 447-457.

62. Wang $\mathrm{Q}$, Mora-Jensen $\mathrm{H}$, Weniger MA, Perez-Galan $\mathrm{P}$, Wolford $\mathrm{C}$, Hai $\mathrm{T}$ et al. ERAD inhibitors integrate ER stress with an epigenetic mechanism to activate $\mathrm{BH}$-only protein NOXA in cancer cells. Proc Natl Acad Sci USA 2009; 106: 2200-2205.

63. Baker SJ, Markowitz S, Fearon ER, Willson JK, Vogelstein B. Suppression of human colorectal carcinoma cell growth by wild-type p53. Science 1990; 249: 912-915.

64. Dignam JD, Lebovitz RM, Roeder RG. Accurate transcription initiation by RNA polymerase II in a soluble extract from isolated mammalian nuclei. Nucleic acids research 1983; 11: 1475-1489.

65. Henriquez B, Hepp M, Merino P, Sepulveda H, van Wijnen AJ, Lian JB et al. C/EBPbeta binds the P1 promoter of the Runx2 gene and up-regulates Runx2 transcription in osteoblastic cells. J Cell Physiol 2011; 226: 3043-3052.

(i) Cell Death and Disease is an open-access journal published by Nature Publishing Group. This work is

licensed under a Creative Commons Attribution 4.0 International License. The images or other third party material in this article are included in the article's Creative Commons license, unless indicated otherwise in the credit line; if the material is not included under the Creative Commons license, users will need to obtain permission from the license holder to reproduce the material. To view a copy of this license, visit http://creativecommons.org/licenses/by/4.0/

Supplementary Information accompanies this paper on Cell Death and Disease website (http://www.nature.com/cddis) 